\title{
How Much Discretion for Risk Regulators? ${ }^{1}$
}

\author{
Yolande Hiriart ${ }^{2}$ and David Martimort ${ }^{3}$
}

31st October 2009

\begin{abstract}
We analyze the regulation of firms that undertake socially risky activities and can reduce the probability of an accident inflicted on thirdparties by carrying out nonverifiable effort. Congress delegates the regulatory task to an Agency, though they may have have different preferences towards the industry. We determine the optimal level of discretion left by Congress to the Agency, showing a trade-off between two effects: the Agency can tailor discretionary policies to its expert knowledge on potential harm, but it implements policies which are too "pro-industry". Although the Agency should be given full discretion when the firm's moral hazard problem is socially costless, partial (and sometimes no) discretion is preferred when moral hazard requires that liability rents be left to regulated firms. Discretion is more valuable with, among other things, less significant conflict of interest between Congress and the Agency, more uncertain distributions of damages in the sense of Blackwell, and when higher-powered incentive regulations are required. We also study how this degree of discretion changes with the political landscape (uncertainty on the Agency's preferences, and strategic appointment by the Executive).
\end{abstract}

Keywords. Risk Regulation, Agencies, Rent/Efficiency Trade-Off, Rules versus Discretion, Organization of the Government.

JEL Classification. D02, D82, H11, L51.

\footnotetext{
${ }^{1}$ We thank Marie-Pierre Boé for assistance and the Agence Nationale pour la Recherche for its financial support. We also thank seminar participants at the Max Plank Institute in Bonn, EAERE in Gothenburg, ASSET Meeting in Florence, AFSE Thematic Meeting in Toulouse, CSEF-IGIER in Capri, and ESEM in Barcelona for helpful comments. All errors are ours.

${ }^{2}$ Toulouse School of Economics (IDEI-LERNA).

${ }^{3}$ Toulouse School of Economics (IDEI-GREMAQ) and EHESS.
} 


\section{Introduction}

Risk regulation differs significantly from one domain to the other not only because of the economic costs and benefits at stake, but also in terms of the actual design of regulatory institutions, the mandate of agencies, and the kind of regulatory procedures they follow. ${ }^{1}$ When Congress enacts a new agency or grants new responsibilities to an existing agency to deal with a particular area of concern, it defines its statutory mandate. In some fields, such mandates leave agencies with significant discretion in setting up standards and fines for misconduct, homologating new products and granting licenses. In other circumstances, safety standards are mandatory, fines do not vary much and strict norms apply uniformly across various domains and market conditions.

Evidence on both sides is pervasive. The statutory mandate of many agencies especially in the areas of health, safety and the environment- is strikingly broad and nonspecific. Section 6 of the Toxic Substances Control Act stipulates that the U.S. Environmental Protection Agency (EPA) should control chemicals that pose "unreasonable risk of injury to health or the environment" without defining what is meant by "unreasonable risk", thereby leaving considerable discretion to EPA to determine which risks are deemed reasonable and which are not. More generally, Van Houtven and Cropper (1996) reported evidence that EPA enjoyed significant discretion in setting up regulatory standards to control chemical risks, taking into account in its decision process both costs and benefits based on its expertise. In a similar vein, and confirming the huge discretion de facto left to the EPA when controlling Superfund sites, Hird (1993, 1994) also reported that the relevant Congressional oversight committee had little or no impact on the pace of cleanups, even at sites located in districts of that committee's members. On the other hand, the Occupational Safety and Health Act has forced the corresponding agency to adopt safety standards as mandatory regulations, ignoring any cost-benefit analysis that could have exploited its expert information. Also, an often observed and controversial feature of liability regimes is that agencies face upper bounds in the damages that firms should cover for the harm inflicted on third-parties or on the environment. The Price-Anderson Act in the U.S. and the Nuclear Liability Act in Canada are examples of regulations that impose such limits for operators of nuclear power stations involved in off-site damages. ${ }^{2}$ Similar limits are also found for oil pollution. ${ }^{3}$

Although delegation to administrative agencies has sometimes be viewed as a violation of the so-called "Delegation Doctrine", arguing that legislative powers cannot be

\footnotetext{
${ }^{1}$ Hood, Rothstein and Baldwin (2003) provide an extensive account of the variety of institutions found in risk regulation.

${ }^{2}$ Heyes and Liston-Heyes (2000) stress the political economy aspect of such limits on fines and argue that this can be viewed as an implicit subsidy for the operators.

${ }^{3}$ Jin and Kite-Powell (1999).
} 
granted to administrative agencies, the number of administrative agencies has increased dramatically over the years and agency decision-making has become the principal means of Federal regulation in the U.S.. According to Ashford and Caldart (2008), "broad delegations of substantive authority to administrative agencies have become the rule rather than the exception." Hence, much delegation does take place and the issue of understanding why remains unsettled. Changes in the nature of the regulated risk and the kind of political forces at play might certainly explain why agencies differ in terms of how much discretion they are left with. To understand how it is the case, we analyze the two-tier relationship between Congress, an Agency, and firms concerned by risk regulation. Such an analysis will help us to assess first, how much freedom should be left to risk regulators and, second, how economic and political forces shape this discretion.

The bottom line of our analysis is that restrictions on the Agency's discretion solve an agency problem between that Agency and Congress. This idea has been a recurring theme of the political science literature over recent years. ${ }^{4}$ For instance, Epstein and O'Halloran (1999) proved a version of the "Ally Principle" showing (and confirming through some empirical analysis) that more delegation should occur when Congress and agencies have closer preferences. ${ }^{5}$ However, and this is the novel insight of our paper, this conflict of interest between Congress and the Agency is not a priori given, as is assumed in the earlier political science literature, but endogenous. This conflict finds its roots in the informational constraints that limit the choice of regulatory instruments. It only arises because asymmetric information, and especially downstream moral hazard on the regulated firm's level of safety care, induces second-best regulations. Although Congress and the Agency agree on regulatory policies when downstream moral hazard is costless, they do disagree when it is costly. Analyzing how this conflict between public bodies arises is key to understand the optimal level of discretion. The agency problems upstream between public bodies and downstream with regulated firms should be studied altogether.

Basic ingredients. To provide some intuition about our results, let us briefly give an overview of our model. Consider a firm involved in activities that put society or the environment at risk. The likelihood of an accident can be reduced if the firm exercises some level of safety care. This effort is nonverifiable and privately costly although socially

\footnotetext{
${ }^{4}$ Although the so-called Congressional Dominance Theory (McCubbins and Schwartz, 1984, and Weingast and Moran, 1983) and the Shift The Responsibility approach (Fiorina, 1982) both pushed the view that Congress could perfectly control Agencies, McCubbins, Noll and Weingast (1987, 1989) already pointed out the role of congressional ex ante control in curbing bureaucratic drift. As convincingly argued by Epstein and O'Halloran (1999, p. 74), the assumption of complete information between Congress and the Agency seems quite at odds with the mere observation that not everything is delegated.

${ }^{5}$ Huber and Shipan (2006) provided a nice survey of the political science literature built on that Principle. Note however this literature often obtains the "Ally Principle" by restricting the kind of ex ante instruments that Congress can use to curb the Agency's behavior. No such restrictions are made in our analysis below, since our mechanism design approach allows a full description of the set of allocations available under informational constraints.
} 
attractive. Moral hazard calls for corrective policies. An incentive regulation is designed to properly incentivize the firm to carry out prevention effort. Congress delegates to some extent the tasks of choosing and implementing the regulatory policy to an Agency. Such delegation is justified in the first place by the fact that the Agency has all the expertise to tailor incentive payments to the potential realizations of harm, and has thereby an informational advantage vis-à-vis Congress. However, the Agency and Congress may have different objectives and the regulatory mandate can be constrained by Congress.

Full discretion in the absence of downstream moral hazard. Suppose first that the firm has enough wealth to cover any harm its activities might inflict on the rest of society. Downstream moral hazard can then be solved at no cost by making the firm "residual claimant": 6 the deep-pocket firm should just pay a Pigovian fine equal to the realized harm. When downstream moral hazard does not induce any distortion, and even though Congress and the Agency may differ in their "pro-industry" biases, they do agree on what this fine should be. Since it allows to use the regulator's expertise, leaving full discretion to the Agency to tailor that fine to losses is optimal.

Partial (or no) discretion otherwise. Things change when the firm's downstream moral hazard is costly. Suppose that the firm has no assets to cover damages and is protected by limited liability. To induce effort, the optimal regulation can no longer punish for bad performances but must now reward for good ones. Consequently, the firm earns some liability rent. When the Agency and Congress have different "pro-firm" biases, they hold different views on the social cost of that rent. Leaving discretion to the better informed and more "pro-firm" regulator becomes costly from the point of view of Congress. More delegation allows better use of the Agency's private information, but it might also trigger regulatory policies which are too "pro-firm" oriented.

Indeed, the "pro-firm" regulator may inflate possible harms in order to make it more attractive to induce the firm's effort, thereby leaving more liability rent. In other words, the downstream agency problem triggers an upstream agency problem between Congress and the regulatory Agency itself. Some ex ante control of the Agency might then be used to limit the scope for such manipulations: Congress imposes an upper bound on the possible rewards that the Agency could use to incentivize the firm. This establishes an information-based version of the "Ally Principle": delegation is more pronounced when Congress and the Agency have more congruent preferences on what the optimal rent/efficiency trade-off under moral hazard should be.

Using the recent mechanism design literature on delegation in organizations, ${ }^{7}$ we characterize the optimal trade-off between "fixing a rule" that applies whatever the level of the

\footnotetext{
${ }^{6}$ See the textbook treatment of moral hazard in Laffont and Martimort (2002, Chapter 4) for instance.

${ }^{7}$ Holmström (1984), Armstrong (1994), Baron (2000), Armstrong and Vickers (2008), Melumad and Shibano (1991), Martimort and Semenov (2006, 2008) and Alonso and Matouscheck (2008) among others.
} 
harms that firms can cause, and "leaving discretion" to the Agency to set up an incentive regulation tailored to these losses. Leaving full discretion is no longer optimal: Congress always gains by putting an upper bound on the rewards that the Agency might choose to incentivize firms. This limit binds for the upper tail of the distribution of potential harms since risks are very high, liability rents huge, and conflicts between the pro-firm regulator and Congress most significant. Even worse, large conflicts might call for no delegation at all and fully rigid rules based on expected and not realized harm.

This mechanism design approach characterizes the whole set of delegation policies without imposing any ad hoc restriction (like, for instance, restricting the choice to either full or no delegation). This illuminates the trade-off between rules and discretion in our context. It allows us to investigate how this trade-off changes as the political and economic landscapes are modified. This approach predicts the role that "uncertainty", be it politically or economically induced, plays on the degree of discretion. ${ }^{8}$

Comparative statics. We perform several kinds of comparative statics exercises. Some results, like the "Ally Principle" stressed above, are directly related to the existing conflict of interest between the Agency and Congress. Roughly, the fact that the misalignment between Agency and Congress endogenously arises from informational problems with regulated firms is not the key aspect of the analysis. Similar comparative statics could as well have been obtained with a more ad hoc modeling that would short-cut the precise origin of this conflict and assume upfront that the Agency and Congress disagree about some policy dimension. In our specific context of risk regulation, the main value of these exercises is that they help to understand how changes in the distribution of losses on which the Agency has private information affect the optimal degree of discretion.

Other comparative statics exercises are more specific to the endogenous source of this conflict, i.e. to the existing moral hazard problem on the regulated firms' side. For instance, we discuss how changes in the information structures, or in the intensity of the Agency's monitoring of the firm's effort affect the optimal level of discretion. Our main result here is that discretion is more valuable as incentive regulation is more efficient.

Extensions. We then investigate how the trade-off between rules and discretion is modified in more complex political environments. First, we consider the case where the Agency has private information on its preferences at the time Congress enacts a regulation. This extra degree of asymmetric information restricts even further the Agency's discretion. Second, we turn to a more detailed analysis of the appointment process. The Executive may strategically appoint a regulator with less pronounced pro-firm preferences than its own in order to soften congressional control and increase ultimately the Agency's discretion.

Literature review. Our paper belongs to and deepens several trends of the literature.

\footnotetext{
${ }^{8}$ This theme echoes the important works of political scientists like Moe (1989) and Horn (1995).
} 
The New Economics of Regulation (Baron and Myerson, 1982, Lewis and Sappington 1988, Laffont and Tirole, 1993, Laffont 1994) assumes that the regulator's preferences are exogenously given and, most often, that there is no conflict of interest between the Agency and Congress, both taken as a single entity. The main focus is on the design of optimal incentive regulations under informational constraints. These regulations generally use all information available to regulators and, as a result, the literature has sometimes been criticized for predicting policies which are too flexible. ${ }^{9}$ Introducing, as we do hereafter, a difference in the preferences of Congress and the Agency over the rent/efficiency trade-off paves the way to a renewed analysis. Optimal regulations end up being quite rigid.

Laffont and Tirole (1993, Chapters 11 and following), among others, have opened the black-box of the relationship between Congress and agencies. They argued that regulatory capture is at the source of the conflict between different layers of the government. We share with this approach the view that this conflict is better solved with optimal policies that are less sensitive to the regulator's expert information. However, in Laffont and Tirole (1993), a reduced discretion never boils down to a completely rigid rule as in our analysis. A major difference between this line of research and ours is that the former relies on the possibility for Congress to incentivize regulators with some kind of performance pay. ${ }^{10}$ Instead, our focus on "rules versus discretion" does not rely on such a possibility. This seems a more appropriate modeling of the crude control that Congress exerts on agencies through legislation and restrictions in procedures.

Other authors have analyzed how various political games influence the preferences of regulators. Using a median-voter theorem, Baron (1989) pointed out that preferences on the rent/efficiency trade-off are inherited from the equilibrium between political forces within the legislature. Laffont (2000) argued that a constitutional commitment to fully rigid regulations may be preferred to a solution leaving more discretion to elected political principals when these principals differ in their preferences on the rent/efficiency tradeoff. Simple standards may be ex ante preferable to optimal incentive regulations because they come "on average" closer to the interim efficiency Pareto frontier. ${ }^{11}$ Our results obviously share some flavor of this idea, though several noticeable differences remain. First, Laffont's framework does not distinguish between elected political principals and agencies. ${ }^{12}$ Second, the "rule" to which more discretionary policies are compared to is

\footnotetext{
${ }^{9}$ The literature on countervailing incentives (see for instance Lewis and Sappington, 1989) has nevertheless shown that optimal mechanisms may exhibit pooling, and appear quite rigid in specific environments where privately informed agents are torn between contradictory incentives.

${ }^{10}$ Sometimes, this assumption is motivated as being only a modeling short-cut to capture the regulator's career concerns.

${ }^{11}$ Boyer and Laffont (1999) applied this idea to environmental regulation.

${ }^{12}$ On this point, Faure-Grimaud and Martimort (2003) analyzed how the scope for regulatory capture depends on the relationships between short-term political principals, whose identity may fluctuate upon elections, and long-term independent agencies.
} 
exogenously given whereas it is endogenous in our setting.

As we argue below, the trade-off between imposing rules on agencies or leaving them with considerable discretion opens strategic possibilities for the Executive through the appointment process. The idea that the Executive can strategically choose an agent is reminiscent of several branches of economics going from industrial organization (Besanko and Spulber, 1993) to macroeconomics and public finance (Rogoff, 1985, Persson and Tabellini, 1993). Governments or society at large may solve a commitment problem by delegating control to agencies with different preferences than their own. Commitment per $s e$ is not an issue in our context. Instead, the compounding of the Agency's expertise and of conflicting interests between different branches of the government is the source of the incentive problem that a partial delegation may solve.

Organization of the paper. Section 2 presents the model. Section 3 shows that the conflict of interests between Congress and the Agency is irrelevant when the firm's moral hazard problem can be solved at no cost. Full discretion should then be left to the Agency. Section 4 demonstrates that such a conflict arises when downstream moral hazard induces a rent/efficiency trade-off. Partial discretion follows. Section 5 provides comparative statics exercices related either to the distribution of harm or to the importance of the firm's moral hazard problem. Section 6 investigates how the level of discretion is affected by various political parameters like asymmetric information on the regulator's ideological preferences, or the Executive's preferences in the appointment process. Section 7 briefly concludes by pointing out alleys for further work. Proofs are relegated to an Appendix.

\section{The Model}

We consider the relationship between a firm whose risky activities might be harmful for society, an Agency and Congress. ${ }^{13}$ Our framework has a broad appeal and applies equally well to all kinds of risk regulation (environmental regulation, product safety, medical malpractice, industrial or transportation safety, nuclear power plant regulation, etc...).

Moral hazard. By implementing some precautionary level of effort $e \in[0,1]$, the firm reduces the probability $1-e$ that third-parties suffer losses of size $D$ following an accident. Carrying out effort entails a non-monetary cost $\psi(e)$ for the firm, with $\psi(\cdot)$ satisfying the Inada conditions $\left(\psi^{\prime}(0)=0, \psi^{\prime}(1)=+\infty, \psi(0)=0\right) .{ }^{14}$ The disutility function $\psi(\cdot)$ is

\footnotetext{
${ }^{13}$ To fix ideas, one may think of a vessel shipping toxic products and whose leakages might create significant environmental losses. Another example could be firms involved in producing GMOs potentially harmful for existing species.

${ }^{14}$ The Inada conditions ensure interior optima under all circumstances below. Sometimes, it will be easier to get comparative statics results by using the quadratic form $\psi(e)=\frac{\lambda}{2} e^{2}$, in which case we will assume that $\lambda$ is large enough to ensure that optimal efforts lie within the open interval $(0,1)$.
} 
increasing and convex $\left(\psi^{\prime}(e)>0, \psi^{\prime \prime}(e)>0\right)$ and satisfies $\psi^{\prime \prime \prime}(e) \geq 0$. The level of safety care is non-observable by either the Agency or any third-party, so that moral hazard might increase the risk of a potential harm occurring.

The firm is protected by limited liability and is endowed with a stock of assets whose value falls short to fully compensate the victims for the harm done. To simplify exposition, we assume that the firm has no assets. Limited liability cum the non-verifiability of effort make it impossible to let the firm internalize the externality that its activities might inflict on third-parties. These assumptions are key to justify the existing liability rent that accrues to the firm and to introduce a conflict of interests between Congress and the Agency.

Contracts. An Agency designs an incentive regulation in order to foster the firm's incentives to exercise care. Without loss of generality, such a regulation stipulates a base payment $t$ from the rest of society to the firm as a reward for its activities ${ }^{15}$ but also a fine $f$ in case a damage occurs.

Even though our analysis relies on the regulator's ability to use transfers in designing the firm's regulation, a broader and less abstract interpretation of our modeling is available. Fines may not only be viewed as payments given by the firm to compensate victims, but they may also include reputational stigma borne following an accident ${ }^{16}$ and more generally be considered as continuation values of the relationships with contractual partners, investors, lenders, etc... Along the same lines, the Agency's choice of incentive rewards and fines could be replaced by its ability to harden or soften future regulations when either canceling or permitting the firm's new products and activities for instance. ${ }^{17}$ With these interpretations in mind, it becomes easier to map our findings with existing regulatory practices. For instance, an Agency that only controls safety standards and, a priori does not directly affect the firm's financial incentives, may implement lax standards in the future as an imperfect substitute for monetary rewards.

Players' objectives. With these notations in hand, it is straightforward to rewrite the firm's expected profit $U$ as:

$$
U=t-(1-e) f-\psi(e)
$$

Let us denote by $S$ the gross surplus generated by the firm's activities. Merging consumers and victims as a unique entity (the "rest of society"), its expected payoff $V$

\footnotetext{
${ }^{15}$ The assumption that the base payment $t$ is controlled by the risk regulator is only made for simplicity. More generally, this base payment might be determined through product market interactions. For instance, it could be fixed by an economic regulator distinct from the risk regulator, or reflect the extent of competition on the product market and be driven by market/supply considerations.

${ }^{16}$ This reputation can ultimately affect the consumers' behavior or the stock market value of the firm.

${ }^{17}$ Hiriart and Martimort (2006) provided more motivation for the short-cut of using monetary transfers between the Agency and the regulated firm in the case of risk regulation.
} 
can be written as: ${ }^{18}$

$$
V=S-t+(1-e)(f-D)
$$

The Agency is appointed by the Executive branch of the government and its objective thus reflects the preferences of that branch. ${ }^{19}$ It is a weighted sum of consumers/victims' payoff and the firm's profit:

$$
W_{R}=V+\alpha_{R} U, \quad \text { with } 0 \leq \alpha_{R}<1 \text {. }
$$

The fact that the firm's profit receives a weight strictly less than one in the regulator's objective function captures the idea that the welfare of the "rest of society" is a greater concern for the regulator. As already well-known, ${ }^{20}$ this assumption guarantees that the optimal regulation trades off efficiency and rent extraction.

Congress' preferences are slightly different and are written as:

$$
W_{C}=V+\alpha_{C} U, \quad \text { with } 0 \leq \alpha_{C}<\alpha_{R}<1
$$

Congress gives less weight than the Agency to the firm's profit. This assumption reflects the possible capture of the Executive and Administrative branches of the government by private interests, and the greater influence that these interests may consequently have on these branches. ${ }^{21,22}$ It may also be viewed as a short-cut for the carrierist concerns of the regulator who may want to please the industry to open "revolving doors". Last, and borrowing Baron (1989)'s view that enacted policies reflect the preferences of the median voter in Congress, this assumption may be relevant when this median voter comes from a district where the firm's business is not significant. This also makes sense when representatives who belong to the Committee in charge of overseeing the Agency are not from districts where the firm locates its activities.

We denote by $\Delta \alpha=\alpha_{R}-\alpha_{C}>0$ the measure of the conflict of interest between Congress and the Agency.

\footnotetext{
${ }^{18}$ Note that this expression makes it clear that fines are transferred at no cost from the firm to victims. It would be straightforward to include a cost of public funds $\lambda$ in our framework so that (2) would become:

$$
V=S-(1+\lambda) t+(1-e)((1+\lambda) f-D) .
$$

The lessons of our model would carry over by rescaling both damages and surplus as it can be easily seen by dividing the latter expression by $1+\lambda$.

${ }^{19}$ Section 6.2 analyzes the case where the preferences of the regulator are chosen by the Executive through the appointment process.

${ }^{20}$ Baron and Myerson (1982).

${ }^{21}$ Horn (1995) pointed out that firms whose costs can be affected by health or environmental regulations take a very active interest in the activities of agencies like OSHA and EPA in the U.S.

${ }^{22}$ We will comment in Section 6.3 below on the reverse assumption where Congress is more "pro-firm" than the Agency.
} 
Information and Agency's discretion. To model in a simple way the trade-off between discretion and bureaucratic rules in the design of risk regulation, we assume that the Agency, because of its expertise, has private information on the loss $D .{ }^{23}$ This informational advantage justifies using a regulator in the first place. To further simplify our modeling, we assume that the firm also knows $D .^{24}$

The loss $D$ is drawn from a common knowledge cumulative distribution $H(\cdot)$ over the support $\mathcal{D}=[\underline{D}, \bar{D}](0 \leq \underline{D}<\bar{D} \leq+\infty)$. The atomless and everywhere positive density is denoted by $h(\cdot)$. For technical reasons, we assume that the monotone hazard rate property holds, $\frac{d}{d D}\left(\frac{1-H(D)}{h(D)}\right)<0$. Let $E(\cdot \mid \cdot)$ be the conditional expectation operator.

\section{The Optimality of Discretionary Policies}

As a useful benchmark, let us first consider the case of a deep-pocket firm that can fully cover losses $D$. For simplicity, we first assume that potential damages are also known by Congress, but we relax this assumption later on.

In such contexts, the non-verifiability of the firm's effort does not preclude an efficient regulation. Simple instruments implement the efficient level of care without any agency cost. A Pigovian fine just equal to the realized harm is enough to align private and social incentives to exercise effort. Raising sufficiently its base payment ensures that the firm is ready to participate. Another important point given our concerns in the rest of the paper is that the resulting distribution of payoffs between the firm and the rest of society does not depend on the Agency's objectives. To see more formally why, let us first write the firm's incentive constraint as:

$$
e=\arg \max _{\tilde{e} \geq 0} t-(1-\tilde{e}) f-\psi(\tilde{e}) \quad \text { or } \quad f=\psi^{\prime}(e)
$$

The firm is active when it gets more than its reservation payoff, normalized at zero:

$$
U=t-(1-e) f-\psi(e) \geq 0 .
$$

\footnotetext{
${ }^{23}$ Alternatively, we may as well assume that losses remain to a large extent uncertain even to the regulator at the time of designing regulation. The term $D$ should then be viewed as the expected harm conditional on the regulator's expert information.

${ }^{24}$ Relaxing this assumption would not modify any of our results. Assuming that $D$ is the regulator's private information would introduce an informed principal problem between the regulator and the firm. However, since the loss $D$ does not enter directly into the firm's payoff, this would be a private values context. We know from Maskin and Tirole (1990) that, with a risk-neutral principal, private information on $D$ would not introduce any distortion with respect to the case where $D$ is common knowledge. It should nevertheless be noticed that we are implicitly restricting the analysis to the case where revelation mechanisms that would use the separate reports of both the regulator and the firm on the value of the commonly observed loss $D$ are not available. One standard justification for this assumption is that opening direct communication channels between Congress and the firm might be too costly.
} 
Expressing the base payment $t$ from the rest of society to the firm as a function of $U$, we may finally write the regulator's optimization problem as:

$$
\left(\mathcal{P}_{R}\right): \max _{\{U, e\}} S-(1-e) D-\psi(e)-\left(1-\alpha_{R}\right) U \text { subject to }(5)
$$

The solution to this problem is summarized in the next proposition.

Proposition 1 Absent liability constraints on the firm's side, the optimal risk regulation:

- Is independent of the Agency's preference parameter $\alpha_{R}$;

- Implements the first-best level of effort $e^{*}(D)$ with a Pigovian fine equal to losses

$$
f^{*}(D)=D=\psi^{\prime}\left(e^{*}(D)\right)
$$

- Extracts all possible rent from the firm (i.e. (5) is binding)

$$
U^{*}(D)=0
$$

When downstream moral hazard is costless, there is no trade-off between efficiency and rent extraction, even if the firm's effort remains non-verifiable. The regulatory policy is independent of the Agency's own preferences and it thus perfectly fits Congress' preferences.

An obvious corollary of Proposition 1 is that the Agency's private information on $D$ is by itself not an issue since it does not introduce any extra agency problem between that Agency and Congress. Whatever the value of $D$, the Agency uses its expert knowledge to implement both the efficient level of effort $e^{*}(D)$ and induce the proper distribution of payoffs between the firm and the rest of society. This leads to the following important property.

Proposition 2 When downstream moral hazard on the firm's side is costless, leaving full discretion to the Agency is optimal whatever its preferences and those of Congress.

On top of the Pigovian fine $f^{*}(D)=D$ that induces the firm to correctly internalize the impact of its safety care on the probability of a damage, a base payment $t^{*}(D)$ such that $t^{*}(D)=\left(1-e^{*}(D)\right) D+\psi\left(e^{*}(D)\right)$ ensures the firm's participation. The firm's net payment in case of accident is negative with such a policy: $t^{*}(D)-f^{*}(D)=-e^{*}(D) \psi^{\prime}\left(e^{*}(D)\right)+$ $\psi\left(e^{*}(D)\right)<0$ since $\psi(\cdot)$ is convex. Hence, this policy is not feasible when the firm has no assets. This is precisely the case that is our focus in the sequel. 


\section{Liability Rent and Endogenous Conflict between the Agency and Congress}

Let us now consider the more interesting case where the firm is insolvent but protected by limited liability, i.e. fines cannot exceed the firm's base payment in our setting. The following limited liability constraint must be satisfied:

$$
t-f \geq 0 \text {. }
$$

Using the definition of the firm's payoff and the moral hazard incentive constraint $\psi^{\prime}(e)=f$, this limited liability constraint can be rewritten more compactly as:

$$
U \geq R(e)
$$

where $R(e)=e \psi^{\prime}(e)-\psi(e)$. In what follows, the term $R(e)$ will be referred to as the firm's liability rent. Note that $R(e) \geq 0$ since $R(0)=R^{\prime}(0)=0$ with $R^{\prime}(e)=e \psi^{\prime \prime}(e)>0$ and $R^{\prime \prime}(e)=e \psi^{\prime \prime \prime}(e)+\psi^{\prime \prime}(e) \geq 0$. Due to the non-verifiability of effort and the potential insolvency of the firm, a rent $R(e)$ must be given up if one wants to induce a given level of effort $e$. The higher the effort one wants to implement, the higher the rent received by the firm. More precisely, a higher effort requires a higher fine $f$ and, since the limited liability constraint is binding, an equal increase in the firm's base payment $t$. The latter being socially costly, this is the source of a rent/efficiency trade-off. ${ }^{25}$

\subsection{Full Discretion Again}

If the Agency had full discretion in choosing the regulatory policy, it would solve the following problem:

$$
\left(\mathcal{P}_{R}^{L}\right): \max _{\{U, e\}} S-(1-e) D-\psi(e)-\left(1-\alpha_{R}\right) U \text { subject to }(8) .
$$

Optimizing $\left(\mathcal{P}_{R}^{L}\right)$ leads to the following proposition.

Proposition 3 Under limited liability, the optimal regulation when the Agency has full discretion:

- Depends on the Agency's preference parameter $\alpha_{R}$;

- Implements a second-best level of effort $e^{S B}\left(\alpha_{R}, D\right)$ which is increasing with $\alpha_{R}$ and $D$ and such that

$$
D=\psi^{\prime}\left(e^{S B}\left(\alpha_{R}, D\right)\right)+\left(1-\alpha_{R}\right) R^{\prime}\left(e^{S B}\left(\alpha_{R}, D\right)\right) ;
$$

\footnotetext{
${ }^{25}$ The firm's participation constraint (4) is implied by (8) and will thus be omitted in the sequel.
} 
- Leaves to the firm a positive rent which is also increasing with $\alpha_{R}$ and $D$

$$
U^{S B}\left(\alpha_{R}, D\right)=R\left(e^{S B}\left(\alpha_{R}, D\right)\right)
$$

When the firm is protected by limited liability, it can no longer be residual claimant for the harm caused. Downstream moral hazard now entails agency costs in the optimal regulation. There is a trade-off between extracting the firm's liability rent and achieving efficiency. The first objective calls for distorting downward the firm's effort, contradicting thereby the second one. Under limited liability, the firm can no longer be punished for bad performances ((8) is binding) and the only way to provide incentives is to increase the base payment $t$ that the firm keeps when no such harm arises. This amounts to leaving a rent $R(e)$. This rent is viewed as costly by the Agency since $\alpha_{R}<1$. To reduce this rent, the firm's effort is distorted downward as shown in (9).

Because it gives a lower weight than the Agency on the firm's profit in its objective function $\left(\alpha_{C}<\alpha_{R}\right)$, Congress would prefer a higher distortion of effort and a smaller rent. The "pro-firm" Agency excessively tilts the rent/efficiency trade-off towards too much efficiency, leaving more rent to the firm compared to what Congress would do. ${ }^{26}$

The downstream agency problem introduces a trade-off between efficiency and rent extraction so that the preferences of Congress and the Agency are no longer aligned in this second-best world. The downstream agency problem trickles up the hierarchy, creating an agency problem between Congress and the Agency itself. The benefit of leaving more discretion to the Agency is that regulatory policies are tailored to its expertise on potential harm, but the cost is that these policies favor excessively the firm.

\subsection{Ex ante Optimal Constraints on Regulatory Agency}

To better align the regulator's objectives with its own in this second-best world, Congress can design ex ante legislation and rules that put constraints on the Agency's discretion. To understand this control, consider first the case where an exogenous constraint on the firm's possible reward $t$ for good environmental performances is imposed by Congress.

A fully rigid rule. Suppose first that Congress forces the Agency to enforce a fixed reward/punishment $t_{C}=f_{C}$ (where the equality follows from the binding liability constraint

\footnotetext{
${ }^{26}$ One may find a bit paradoxical the result that a pro-firm Agency, which wants to give more rent to the firm, applies higher fines and implements higher levels of safety care. Remember that, under limited liability, higher fines are covered by higher base payments and incentive rewards. Our interpretation of such incentive rewards as coming from implementing lax regulations in the future offers a response to this seemingly paradoxical result. More generally, the whole incentive regulation literature (Baron and Myerson, 1982, Laffont and Tirole, 1993, Armstrong and Sappington, 2007) makes the point that high-powered incentives also leave lots of information rent to privately informed firms.
} 
(7)) such that:

$$
t_{C}=f_{C}=\psi^{\prime}\left(e_{C}\right) \text { with } E(D)=\psi^{\prime}\left(e_{C}\right)+\left(1-\alpha_{C}\right) R^{\prime}\left(e_{C}\right),
$$

and where $E(D)$ is the average loss. This non-discretionary policy corresponds to the ex ante rule that would be chosen by Congress without any expert information. ${ }^{27}$ The Agency has no choice except to implement that rule. The benefit of such a rigid rule is that the rent/efficiency trade-off is evaluated according to Congress' preferences. Its cost is that the Agency's expertise on potential harm is not used.

Mechanism design. Let us now take a more general perspective. We want to describe the whole set of incentive mechanisms that might limit the Agency's discretion and still may make use of its expertise, at least over some ranges of possible realizations of $D$. In looking for such a characterization, we follow the literature that models delegation in organizations as a mechanism design problem ${ }^{28}$ and derive the optimal ex ante limit on what the Agency can do without imposing any ad hoc restriction on delegation pattern. ${ }^{29}$

A direct mechanism can a priori be viewed as a collection of transfers $\{t(\hat{D})\}_{\hat{D} \in \mathcal{D}}$ contingent on the regulator's announcement $\hat{D}$ on the level of possible harm. From the Revelation Principle, there is no loss of generality in considering such direct and truthful mechanisms. Alternatively, such mechanisms stipulate a range of possible transfers from which the regulator can choose. This interpretation in terms of delegation sets, i.e. in terms of the range of mechanisms $\{t(\hat{D})\}_{\hat{D} \in \mathcal{D}},{ }^{30}$ stresses the role that Congress plays in restricting ex ante the possible options available to the Agency. ${ }^{31}$ Since $t=f$ from the binding limited liability constraint (7), any upper bound on rewards that would be impose by such a mechanism can alternatively be viewed as a lower bound on punishments.

Alternatively, given the one-to-one mapping between rewards and effort that comes out of the firm's incentive constraint (4) (with again $t=f$ ), we may as well consider that those

\footnotetext{
${ }^{27}$ This policy is similar to the ex ante policy based on average harm in Shavell (1984).

${ }^{28}$ Holmström (1984), Melumad and Shibano (1991), Armstrong (1994), Baron (2000), Martimort and Semenov (2006, 2008) and Alonso and Matouscheck (2008).

${ }^{29}$ For instance, an ad hoc restriction would be to allow either always full or no discretion at all.

${ }^{30}$ This interpretation is based on the so-called Taxation Principle that mirrors the Revelation Principle and replaces the direct revelation mechanism by an indirect one where the agent has to choose within the set of relevant options that the corresponding direct revelation mechanism was offering.

${ }^{31}$ Two restrictions are made with respect to the largest possible class of mechanisms. First, and for the sake of realism, we focus on deterministic mechanisms. Congress is not allowed to offer possible lotteries of rewards among which the regulator could choose from. Kovac and Mylovanov (2007) analyzed conditions under which such stochastic mechanisms are not optimal. Laffont and Martimort (2002) argued that stochastic mechanisms require the ability to commit to use a public randomizing device which could be manipulated, making those mechanisms less credible than deterministic ones. Our second restriction is our focus on continuous mechanisms (or alternatively on delegation sets which are connected). As we will see below, these mechanisms have a nice and quite tractable characterization. Melumad and Shibano (1991), Martimort and Semenov (2006), Alonso and Matouscheck (2008) and Kovac and Mylovanov (2007) have provided various conditions on type distributions and utility functions ensuring such a continuity.
} 
mechanisms stipulate the level of effort that the Agency implements in response to its private information. Although effort is non-verifiable, we will slightly abuse terminology and denote such mechanisms as $\{e(\hat{D})\}_{\hat{D} \in \mathcal{D}}$.

Given its expert knowledge of the potential harm $D$, implementing effort $e(\hat{D})$ yields the following payoff to the Agency:

$$
W_{R}(\hat{D}, D)=S-(1-e(\hat{D})) D-\psi(e(\hat{D}))-\left(1-\alpha_{R}\right) R(e(\hat{D})) .
$$

The incentive compatibility constraints which are necessary to induce truthtelling by the Agency can thus be written as:

$$
D \in \arg \max _{\hat{D} \in \mathcal{D}} W_{R}(\hat{D}, D)
$$

From standard revealed preferences arguments, we obtain the following Lemma.

Lemma 1 Any incentive compatible mechanism $\{e(\hat{D})\}_{\hat{D} \in \mathcal{D}}$ is such that $e(D)$ is monotonically increasing in $D$ and thus almost everywhere differentiable with, at any differentiable point,

$$
\begin{gathered}
\dot{e}(D) \geq 0, \\
\dot{e}(D)\left(D-\psi^{\prime}(e(D))-\left(1-\alpha_{R}\right) R^{\prime}(e(D))\right)=0 .
\end{gathered}
$$

The monotonicity condition (12) implies that, as the level of harm increases, the firm's effort also increases. This is a quite natural condition which is satisfied, for instance, by the outcome $e^{S B}\left(\alpha_{R}, D\right)$ obtained when the Agency has full discretion. The firstorder condition (13) for truthtelling tells us that the optimal reward is either flat and independent of the harm level, or corresponds to the Agency's ideal policy. In this case, the Agency uses its discretion to tailor the firm's incentive reward to the level of harm.

The characterization of continuous mechanisms is then straightforward.

Lemma 2 Any implementable policy $\{e(D)\}_{D \in \mathcal{D}}$ that is continuous is fully characterized by two thresholds $D_{*}$ and $D^{*}$ such that $\underline{D} \leq D_{*} \leq D^{*} \leq \bar{D}$ and:

$$
\left.e(D)=\min \left\{\max \left\{e^{S B}\left(\alpha_{R}, D\right), e^{S B}\left(\alpha_{R}, D_{*}\right)\right\}, e^{S B}\left(\alpha_{R}, D^{*}\right)\right\}\right\}
$$

The amount of discretion left to the regulator is bounded above by a cap on rewards, $\left.t^{S B}\left(\alpha_{R}, D^{*}\right)=\psi^{\prime}\left(e^{S B}\left(\alpha_{R}, D^{*}\right)\right)\right)$, and below by a floor, $t^{S B}\left(\alpha_{R}, D_{*}\right)=\psi^{\prime}\left(e^{S B}\left(\alpha_{R}, D_{*}\right)\right)$. Within this interval, the Agency has full discretion in setting up incentive rewards according to its own preferences. Our goal is essentially to find these bounds. 
To provide more intuition on the limits to the Agency's discretion, we now investigate the kind of incentives it would have for manipulating its announcement $\hat{D}$ on potential harm if Congress's ideal policy $e^{S B}\left(\alpha_{C}, \hat{D}\right)$ was implemented. We find:

$$
\begin{aligned}
\left.\frac{\partial}{\partial \hat{D}} W_{R}(\hat{D}, D)\right|_{\hat{D}=D} & =\left.\frac{\partial e^{S B}}{\partial D}\left(\alpha_{C}, \hat{D}\right)\left(D-\psi^{\prime}\left(e^{S B}\left(\alpha_{C}, \hat{D}\right)\right)-\left(1-\alpha_{C}\right) R^{\prime}\left(e^{S B}\left(\alpha_{C}, \hat{D}\right)\right)\right)\right|_{\hat{D}=D} \\
& =\Delta \alpha \frac{\partial e^{S B}}{\partial D}\left(\alpha_{C}, D\right) R^{\prime}\left(e^{S B}\left(\alpha_{C}, D\right)\right)>0 .
\end{aligned}
$$

The mechanism $\left\{e^{S B}\left(\alpha_{C}, D\right)\right\}_{D \in \mathcal{D}}$ is not incentive compatible. The Agency finds it always optimal to inflate potential harm. By doing so, the "pro-firm" regulator chooses higher levels of effort and increases the firm's rent. This suggests that there is no reason to fix a floor on rewards since the Agency never has an incentive to understate losses. On the other hand, putting a cap certainly helps align the objectives of Congress and those of the Agency. ${ }^{32}$ Therefore, the optimal mechanism is of the form $e(D)=\min \left\{e^{S B}\left(\alpha_{R}, D\right), e^{S B}\left(\alpha_{R}, D^{*}\right)\right\}$ where the level of damage $D^{*}$ below which the Agency keeps discretion is the optimization variable left to Congress.

Under asymmetric information on $D$, Congress' optimization problem becomes:

$$
\begin{gathered}
\left(\mathcal{P}_{R}^{S B}\right): \quad \max _{D^{*} \in \mathcal{D}} S-E\left((1-e(D)) D+\psi(e(D))+\left(1-\alpha_{C}\right) R(e(D))\right) \\
\text { where } e(D)=\min \left\{e^{S B}\left(\alpha_{R}, D\right), e^{S B}\left(\alpha_{R}, D^{*}\right)\right\} .
\end{gathered}
$$

Optimizing $\left(\mathcal{P}_{R}^{S B}\right)$ finally leads to the following proposition.

Proposition 4 The optimal policy can be characterized as follows.

- If $e^{S B}\left(\alpha_{R}, \underline{D}\right) \geq e_{C}$, the Agency has no discretion and implements the effort $e_{C}$ which is ex ante optimal from Congress' viewpoint (rigid rule).

- If $e^{S B}\left(\alpha_{R}, \underline{D}\right)<e_{C}$, the Agency has partial discretion but never full discretion. Congress imposes a cap $e^{S B}\left(\alpha_{R}, D^{*}\left(\alpha_{R}\right)\right)$ on the firm's effort that the Agency may induce, where $D^{*}\left(\alpha_{R}\right) \in(\underline{D}, \bar{D})$ is the unique solution to

$$
E\left(D \mid D \geq D^{*}\left(\alpha_{R}\right)\right)=\psi^{\prime}\left(e^{S B}\left(\alpha_{R}, D^{*}\left(\alpha_{R}\right)\right)\right)+\left(1-\alpha_{C}\right) R^{\prime}\left(e^{S B}\left(\alpha_{R}, D^{*}\left(\alpha_{R}\right)\right)\right),
$$

with $e^{S B}\left(\alpha_{R}, D^{*}\left(\alpha_{R}\right)\right)<e^{S B}\left(\alpha_{C}, \bar{D}\right)$.

The Agency induces an effort $e^{S B}\left(\alpha_{R}, D\right)$ when $D \in\left[\underline{D}, D^{*}\left(\alpha_{R}\right)\right]$ and is constrained by the cap otherwise.

\footnotetext{
${ }^{32}$ This is confirmed in the next proposition with a formal proof in the Appendix.
} 
Putting a cap on rewards better aligns the regulator's choice with Congress' ideal policy. Once the cap is hit, i.e. when the level of harm is high enough and reaches $D^{*}\left(\alpha_{R}\right)$, the optimal regulation is the Agency's ideal policy for a harm equal to $D^{*}\left(\alpha_{R}\right)$, namely $e^{S B}\left(\alpha_{R}, D^{*}\left(\alpha_{R}\right)\right)$ (see Figure 1 below). It is higher than the effort level $e^{S B}\left(\alpha_{C}, D^{*}\left(\alpha_{R}\right)\right)$ that Congress would choose. However, when $D$ increases, such an effort level comes closer to $e^{S B}\left(\alpha_{C}, D\right)$ up to the point where $e^{S B}\left(\alpha_{R}, D^{*}\left(\alpha_{R}\right)\right)$ becomes too low compared with $e^{S B}\left(\alpha_{C}, \bar{D}\right)$ for the most extreme values of $D$. Over the set of possible values of $D$ where a rigid rule applies, the effort is either above or below Congress' ideal choice but on average, when $D^{*}\left(\alpha_{R}\right)$ is optimally chosen, these distortions compensate each other.

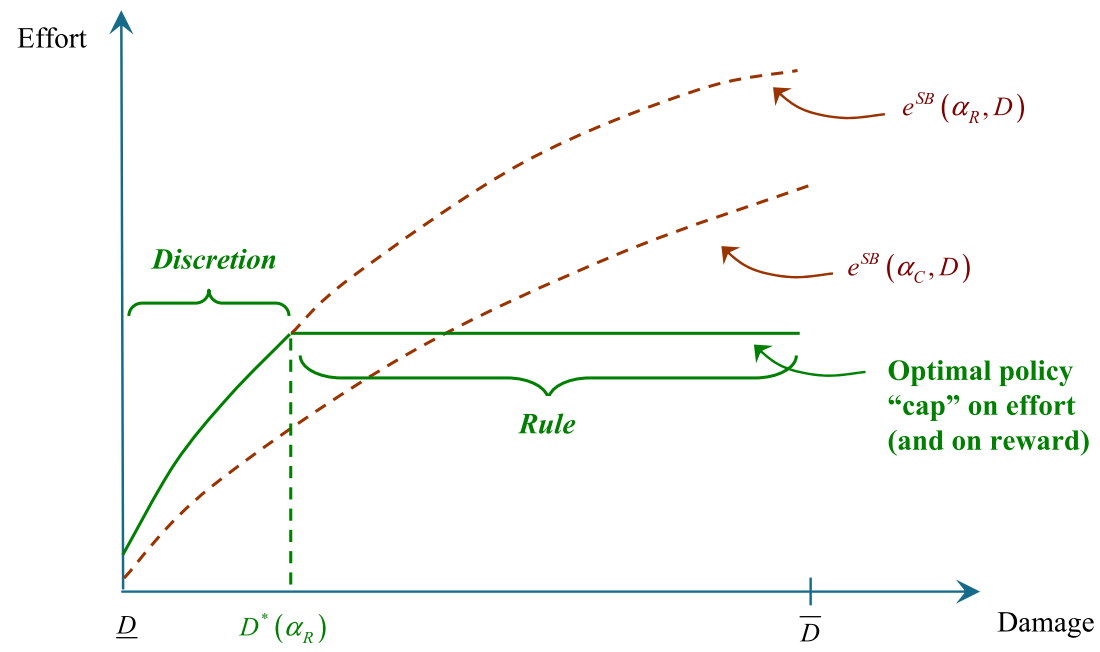

Figure 1

A rigid rule at $e_{C}$ may be optimal when the objectives of the Agency and Congress are sufficiently far apart. More generally, leaving discretion to the Agency over the upper tail of the distribution of harm is never optimal. Indeed, given that $e^{S B}\left(\alpha_{R}, \bar{D}\right)>e^{S B}\left(\alpha_{C}, \bar{D}\right)$, it is optimal to cap the level of effort in the neighborhood of $\bar{D}$ to bring it closer to the Congress' preferences.

Implementation. The optimal solution can be implemented by simply imposing a cap $t^{S B}\left(D^{*}\left(\alpha_{R}\right)\right)=\psi^{\prime}\left(e^{S B}\left(\alpha_{R}, D^{*}\left(\alpha_{R}\right)\right)\right)$ on the rewards that the regulator can choose. Another possible implementation of the optimal mechanism consists in leaving to the Agency the choice of a reward from the interval $\left.\left[\psi^{\prime}\left(e^{S B}\left(\alpha_{R}, \underline{D}\right)\right)\right), \psi^{\prime}\left(e^{S B}\left(\alpha_{R}, D^{*}\left(\alpha_{R}\right)\right)\right)\right]$. This leads to a nice interpretation of how "vague" the Agency's mandate should be. Indeed, this model of delegation could be reinterpreted as an "incomplete contract" model where the delegation set specifies a priori the possible realizations of uncertainty where the Agency has real authority in setting up the regulation. A vague mandate corresponds to a lot of freedom for the Agency, which typically arises when $e^{S B}\left(\alpha_{R}, \underline{D}\right)$ and $e^{S B}\left(\alpha_{R}, D^{*}\left(\alpha_{R}\right)\right)$ are sufficiently far apart, i.e. when the distribution of $D$ is spread enough. Instead, a stricter mandate corresponds to a smaller delegation set. 


\section{Comparative Statics}

We divide this section into two parts. In the first one, we consider how changes in some parameters of the model affect discretion but focus only on those changes related to the upstream agency problem between the Agency and Congress. Although, and we will insist again on it, downstream moral hazard is the source of this upstream agency problem, an ad hoc modeling of the relationship between the Agency and Congress that would shortcut the very origin of the their conflicting preferences over incentive regulations might suffice to get similar insights. In the second part, we analyze more deeply how changes in the intensity of the downstream moral hazard problem with regulated firms affect the Agency's discretion. By definition, these results could not have been obtained with any ad hoc modeling of the upstream agency problem.

\subsection{Upstream Agency Problem}

To sharpen intuition and simplify the comparative statics exercises, consider the parametric case of a quadratic disutility function, $\psi(e)=\frac{\lambda e^{2}}{2}$ with $\lambda$ large enough so that effort remains in $(0,1)$. Then, it is straightforward to check that

$$
e^{S B}\left(\alpha_{R}, D\right)=\frac{D}{\lambda\left(2-\alpha_{R}\right)}
$$

and the first-order condition (15) yields

$$
E\left(D \mid D \geq D^{*}\left(\alpha_{R}\right)\right)-D^{*}\left(\alpha_{R}\right)=\frac{\Delta \alpha}{2-\alpha_{R}} D^{*}\left(\alpha_{R}\right)
$$

"Ally Principle". From (16), we immediately recover the so-called "Ally Principle", i.e. the Agency has more discretion when its objectives are closer to Congress' ones.

Corollary 1 Assume a quadratic disutility function $\left(\psi(e)=\frac{\lambda e^{2}}{2}\right.$ with $\lambda$ large enough to avoid corner solutions). An increase in the conflict of interest between Congress and the Agency (i.e. $\Delta \alpha$ becoming larger) reduces the Agency's discretion (i.e. $D^{*}\left(\alpha_{R}\right)$ diminishes).

Beyond the case of risk regulation which is our concern in this paper, this finding has more generally received significant empirical support in the political science literature (Wood and Bothe 2004, Epstein and O'Halloran 1994, and Huber and Shipan 2002). However, this literature specifies a priori the upstream conflict of interest rather than deriving it from informational limits on policy instruments. ${ }^{33}$

\footnotetext{
${ }^{33}$ As pointed out by Epstein and O'Halloran (1994), this result also suggests that tougher rules are imposed on regulatory agencies in periods of divided governments, when the preferences of Congress and the Executive are further apart.
} 
Comparison of information structures. It is also interesting to investigate how changes in the distribution of damages affect the degree of discretion left to the Agency. An often-found argument in the political science literature ${ }^{34}$ is that more "uncertainty" in the regulatory environment makes it more likely that discretionary power will be delegated to the Agency. This idea, although quite relevant for risk regulation since uncertainty de facto plays a key role, needs to be linked to properties of the distribution of losses. ${ }^{35}$

Front-loading. We say that a distribution $H_{1}(\cdot)$ is more "front-loaded" than a distribution $\mathrm{H}_{2}(\cdot)$ if and only if:

$$
\frac{1}{1-H_{1}(D)} \int_{D}^{\bar{D}} x h_{1}(x) d x \leq \frac{1}{1-H_{2}(D)} \int_{D}^{\bar{D}} x h_{2}(x) d x \text { for all } D \in \mathcal{D}
$$

with equality at $\bar{D}$. This inequality simply means that the conditional expected harm over the upper tail $[D, \bar{D}]$ is always greater with $H_{2}(\cdot)$ than with $H_{1}(\cdot) .{ }^{36}$ Intuitively, $H_{1}(\cdot)$ puts more mass around the lower tail than $H_{2}(\cdot) .{ }^{37}$

Corollary 2 Assume a quadratic disutility function $\left(\psi(e)=\frac{\lambda e^{2}}{2}\right.$ with $\lambda$ large enough to avoid corner solutions). The Agency has more discretion when $D$ is drawn from the distribution $H_{2}(\cdot)$ than when it is drawn from the distribution $H_{1}(\cdot)$ (i.e. $D^{*}\left(\alpha_{R}\right)$ increases) if $H_{1}(\cdot)$ is more front-loaded than $H_{2}(\cdot)$.

Corollary 2 shows that it is not "uncertainty" (as for instance it could be captured by increasing the variance of the distribution of losses) per se that determines the level of discretion left to the Agency. Instead, the optimal level of discretion is linked to finer properties of conditional expectations. A more front-loaded distribution reduces the likelihood of high damages. This means that "large" reports on potential losses can be interpreted by Congress as coming from a regulator who is very likely to have overstated their level. Stricter rules should be implemented and less discretion should be left to the Agency. Domains where risks are relatively minor "on average" should be mostly ruled by norms, whereas more significant risks should be regulated by Agencies having more discretionary power.

\footnotetext{
${ }^{34}$ See Epstein and O'Halloran $(1994,1999)$ and Bawn (1995) for instance.

${ }^{35}$ The political science literature often restricts its study to the binary choice between leaving either full or no discretion to the Agency. What is meant by "the impact of uncertainty on the optimal degree of discretion" in such an environment remains unclear. As shown below, investigating the full impact of a change in the distribution of losses on the optimal degree of discretion requires taking into account the fact that this level is generally in between full and no discretion, and depends itself on the distribution through the optimality condition (16).

${ }^{36} \mathrm{In}$ particular, the average damage is greater with distribution $H_{2}(\cdot)$ than with distribution $H_{1}(\cdot)$.

${ }^{37}$ Consider the exponential distributions on $\mathbb{R}_{+}$such that $H_{i}(D)=1-\exp \left(-\frac{D}{\mu_{i}}\right)$ for $i=1,2$ with $0<\mu_{1} \leq \mu_{2}$. It can be readily verified that (17) holds.
} 
More uncertainty in the sense of Blackwell. We now investigate how the amount of discretion left to the Agency evolves when the distribution of losses is better known, maybe thanks to the evolution of scientific knowledge. This question is particularly relevant in the case of GMOs for instance, where little is known on the consequences of homologating some products at the time of enacting regulations, but knowledge on the distribution of potential losses will improve later on. We model the evolution of scientific knowledge as the arrival of some public information that decreases uncertainty in the sense of Blackwell. Under weak assumptions, leaving more discretion to the Agency is preferable in more uncertain contexts. Instead, risks which are better known require more rigid rules.

Consider thus the case where one of $K$ possible signals on the possible distribution of harm becomes common knowledge. In response to this change in publicly available knowledge, Congress designs new regulations. Denote by $H_{k}(\cdot)\left(\operatorname{resp} . h_{k}(\cdot)\right)$ the cumulative distribution on $\mathcal{D}$ (resp. density) corresponding to signal $k \in\{1, . ., K\}$ and let $x_{k}$ be the positive probability that signal $k$ is realized $\left(\sum_{k=1}^{K} x_{k}=1, x_{k}>0\right)$. From an ex ante viewpoint, i.e. before the arrival of scientific knowledge, the cumulative distribution (resp. density) of losses is $H(D)=\sum_{k=1}^{K} x_{k} H_{k}(D)\left(\right.$ resp. $\left.h(D)=\sum_{k=1}^{K} x_{k} h_{k}(D)\right)$.

Ex post, i.e. once the signal $k$ is observed, the amount of discretion $D_{k}^{*}\left(\alpha_{R}\right)$ left to the Agency is obtained from (16) as:

$$
\frac{1}{1-H_{k}\left(D_{k}^{*}\left(\alpha_{R}\right)\right)} \int_{D_{k}^{*}\left(\alpha_{R}\right)}^{\bar{D}} h_{k}(D) D d D-D_{k}^{*}\left(\alpha_{R}\right)=\frac{\Delta \alpha}{2-\alpha_{R}} D_{k}^{*}\left(\alpha_{R}\right) .
$$

Instead, from an ex ante viewpoint, i.e. without having learned yet about the signal, the optimal amount of discretion $D^{*}\left(\alpha_{R}\right)$ solves (with $E_{k}(\cdot)$ denoting the expectation operator conditional over signals):

$$
\frac{1}{1-E_{k}\left(H_{k}\left(D^{*}\left(\alpha_{R}\right)\right)\right)} \int_{D^{*}\left(\alpha_{R}\right)}^{\bar{D}} E_{k}\left(h_{k}(D)\right) D d D-D^{*}\left(\alpha_{R}\right)=\frac{\Delta \alpha}{2-\alpha_{R}} D^{*}\left(\alpha_{R}\right) .
$$

For the case of exponential distributions having mean $\mu_{k}>0$, density $h_{k}(D)=$ $\frac{1}{\mu_{k}} \exp \left(-\frac{D}{\mu_{k}}\right)$ and cumulative distribution $H_{k}(D)=1-\exp \left(-\frac{D}{\mu_{k}}\right)$, the above formulae are amenable to a straightforward comparison.

Corollary 3 Assume a quadratic disutility function $\left(\psi(e)=\frac{\lambda e^{2}}{2}\right.$ with $\lambda$ large enough to avoid corner solutions) and exponential distributions. More uncertainty in the sense of Blackwell increases the Agency's discretion in the following sense:

$$
E_{k}\left(D_{k}^{*}\left(\alpha_{R}\right)\right) \leq D^{*}\left(\alpha_{R}\right)
$$

The rough intuition for this result comes from observing that the more uncertain distribution $H(\cdot)$ has a conditional expectation on upper tails which is greater "on average" 
than conditional expectations obtained when signals have been revealed. The Agency's claim about high values of $D$ in a more uncertain world is not so unlikely and cannot be interpreted too much as evidence for manipulating information to favor the firm. This relaxes the Agency's truthtelling incentive constraints and calls for more discretion.

More discretion should be left to the Agency at the inception of regulations but, as time goes on and knowledge on the kind of risks run improves, tighter regulations will be enforced "on average". With such tighter regulations, the firm gets "on average" less liability rent. This example suggests that firms might be net losers when scientific knowledge on potential harm increases.

\subsection{Downstream Agency Problem}

Let us now turn to some comparative statics with respect to the intensity of the downstream moral hazard problem.

Noisy performances. Suppose that a "bad" performance, which still occurs with probability $1-e$, can only be observed with probability $(1-\theta)(1-e)(\theta \in(0,1))$. Instead, a "good" performance is observed with probability $e+(1-e) \theta$. This noisy information structure is particularly relevant for environmental regulation. A bad environmental performances might indeed be revealed only with some delay in the future. Then, the firm's incentive constraint under limited liability (where $t=f$ ) can be written as:

$$
e=\arg \max _{\tilde{e} \geq 0} t-(1-\tilde{e})(1-\theta) f-\psi(\tilde{e}) \quad \text { or } \quad(1-\theta) f=\psi^{\prime}(e) .
$$

This leads to the following expression of the firm's information rent

$$
U=R(e)+\eta \psi^{\prime}(e) .
$$

The parameter $\eta=\frac{\theta}{1-\theta}$ captures the informativeness of a good performance on the firm's effort, $\eta$ being greater when such performance is less informative on the firm's effort.

Equation (20) shows that more noise increases the cost of inducing effort and the firm's information rent. It tilts the optimal regulation towards low-powered incentives. Assuming interior solutions, the second-best level of effort $e^{S B}\left(\alpha_{R}, D\right)$ is even more distorted downwards:

$$
D=\psi^{\prime}\left(e^{S B}\left(\alpha_{R}, D\right)\right)+\left(1-\alpha_{R}\right) \psi^{\prime \prime}\left(e^{S B}\left(\alpha_{R}, D\right)\right)\left(e^{S B}\left(\alpha_{R}, D\right)+\eta\right) .
$$

From this, we immediately obtain:

Corollary 4 Assume a quadratic disutility function $\left(\psi(e)=\frac{\lambda e^{2}}{2}\right.$ with $\lambda$ large enough) and that $\eta$ is small enough to ensure a positive effort. Noisier performances reduce the Agency's discretion $\left(D^{*}\left(\alpha_{R}\right)\right.$ decreases as $\eta$ increases). 
To understand this result, remember that the conflict between the Agency and Congress is due to downstream moral hazard. When this downstream agency problem worsens, in particular because of less informative performances, this conflict is exacerbated. The optimal institutional response is thus to leave less discretion to the Agency. Worse agency problems downstream imply worse agency problems upstream.

Informative signals. Suppose that the Agency observes an extra signal $\sigma \in\{\underline{\sigma}, \bar{\sigma}\}$ which is informative on the firm's effort even when there is no accident. More precisely, suppose that with probability $p_{1}(e)=\frac{1}{2}(e+\eta)$ (state 1 ), the accident does not take place and the signal $\underline{\sigma}$ informs the Agency that this is unlikely to be due to a high effort. Instead, with probability $p_{2}(e)=\frac{1}{2}(e-\eta)$ (state 2 ), there is still no accident but the signal $\bar{\sigma}$ informs the Agency that this is likely to be due to a high effort. We assume $\eta>0$ but not too large. With complementary probability $p_{3}(e)=1-e$ an accident occurs (state 3). Under limited liability, it is a standard result of the moral hazard literature ${ }^{38}$ that the optimal incentive scheme should reward the firm only in the state which has the highest likelihood ratio, i.e. in state 2 , which is the most informative on the fact that the firm has exercised some effort. ${ }^{39}$ Therefore, the firm's incentive constraint under limited liability (i.e. $t=f)$ can be written as:

$$
e=\arg \max _{\tilde{e} \geq 0} t-\left(\frac{\tilde{e}+\eta}{2}+1-\tilde{e}\right) f-\psi(\tilde{e}) \quad \text { or } \quad \frac{f}{2}=\psi^{\prime}(e) .
$$

This leads to the following expression of the firm's information rent:

$$
U=R(e)-\eta \psi^{\prime}(e)
$$

Equation (23) is the flip-side of (20). It shows that using an informative signal helps reducing the firm's information rent and pushes towards higher-powered regulation. $M u$ tatis mutandis, we obtain:

Corollary 5 Assume a quadratic disutility function $\left(\psi(e)=\frac{\lambda e^{2}}{2}\right.$ with $\lambda$ large enough) and that $\eta$ is small enough so that state 2 arises with positive probability under all circumstances and the firm's rent remains positive. A more informative signal on the agent's effort increases the Agency's discretion $\left(D^{*}\left(\alpha_{R}\right)\right.$ increases as $\eta$ increases).

The intuition here is the flip side of that for Corollary 4. When $\eta$ increases, state 2 becomes more informative on the firm having done a high effort. Providing incentives is easier. The second-best effort comes closer to the first-best and the conflict between the Agency and Congress is less of a concern. The Agency should be given more discretion.

\footnotetext{
${ }^{38}$ See for instance Laffont and Martimort (2002, Chapter 4).

${ }^{39}$ Note that the likelihood ratio $\frac{p_{2}^{\prime}(e)}{p_{2}(e)}=\frac{1}{e-\eta}$ in state 2 increases with $\eta$ and that $\frac{p_{2}^{\prime}(e)}{p_{2}(e)}>\frac{p_{1}^{\prime}(e)}{p_{1}(e)}>\frac{p_{3}^{\prime}(e)}{p_{3}(e)}$.
} 
Monitoring. Suppose now that the Agency can increase the probability of a good performance by exercising some monitoring. More precisely, assume that, with probability $1-e$, the Agency receives an interim signal that reveals a future damage. With a monitoring effort $\theta$ of a fixed intensity the probability of such an accident can be reduced to $(1-\theta)(1-e)$. For simplicity, let us assume that the Agency's monitoring effort is contractible and exogenous. A good performance (resp. damage) occurs now with probability $e+(1-e) \theta$ (resp. $(1-e)(1-\theta))$. By a standard mechanism, ${ }^{40}$ more monitoring makes the firm's incentives more costly. Its information rent is again given by (20).

Corollary 6 Assume a quadratic disutility function $\left(\psi(e)=\frac{\lambda e^{2}}{2}\right.$ with $\lambda$ large enough) and that $\eta$ is small enough. More monitoring of the agent's effort decreases the Agency's discretion $\left(D^{*}\left(\alpha_{R}\right)\right.$ decreases as $\eta$ increases $)$.

With a more interventionist Agency that can correct the firm's effort early enough to avoid an accident, it becomes harder to provide incentives to the firm. In turn, this move towards low-powered incentives makes it more attractive to choose inflexible rules.

\section{Extensions}

This section proposes several extensions of our basic framework to enrich the modeling of the political sphere, and discuss how the optimal degree of discretion changes thereby.

\subsection{Political Uncertainty and Asymmetric Information on the Agency's Preferences}

Ex ante constraints on agencies may be designed when there is still significant uncertainty on the preferences of the heads of these agencies. This uncertainty may be exogenous and linked to the intrinsic motivation of the bureaucrats in charge. It might also be endogenous to the political process. For instance, such uncertainty might be induced by random changes in the Agency's head (or significant changes in the composition of the Executive Committee). We characterize the optimal trade-off between rules and discretion in such an environment. The analysis is made complex because of the interplay between two pieces of private information that the Agency handles: first, its expertise on the level of harm and, second, its own bias towards the industry. We show that the Agency should be given less discretion as its preferences are less certain, although this effect is only of a second-order magnitude.

\footnotetext{
${ }^{40}$ See Aghion and Tirole (1997) for instance.
} 
To model such settings, we assume that, at the time of designing ex ante constraints on the Agency, the weight $\tilde{\alpha}_{R}$ that the firm receives in the Agency's objective is viewed as random by Congress, with $\tilde{\alpha}_{R}$ being uniformly distributed on an interval $\left[\alpha_{R}-\epsilon, \alpha_{R}+\epsilon\right]$. We assume that $\alpha_{C}<\alpha_{R}-\epsilon<\alpha_{R}+\epsilon<1$ and that $\epsilon$ is small enough so that even the Agency least eager to favor the firm has nevertheless more pronounced pro-firm preferences than Congress. Denote $G_{\epsilon}$ the corresponding cumulative distribution (such that $G_{\epsilon}(\alpha)=$ $\frac{\alpha-\alpha_{R}+\epsilon}{2 \epsilon}$ for $\alpha \in\left[\alpha_{R}-\epsilon, \alpha_{R}+\epsilon\right], G_{\epsilon}(\alpha)=1$ for $\alpha \geq \alpha_{R}+\epsilon, G_{\epsilon}(\alpha)=0$ for $\left.\alpha \in\left[\alpha_{C}, \alpha_{R}-\epsilon\right]\right)$.

In full generality, a deterministic incentive mechanism must now induce the Agency to reveal truthfully all its private information, i.e. not only its expertise but also its own preferences. Such a mechanism is a menu of rewards for the firm $\{t(\hat{\alpha}, \hat{D})\}_{\{\hat{\alpha} \in[\underline{\alpha}, \bar{\alpha}], \hat{D} \in \mathcal{D}\}}$ as a function of the Agency's reports on the level of potential harm it privately observes and on its own preferences. Equivalently, and again using (4), such a mechanism can be viewed as a menu of effort levels $\{e(\hat{\alpha}, \hat{D})\}_{\{\hat{\alpha} \in[\underline{\alpha}, \bar{\alpha}], \hat{D} \in \mathcal{D}\}}$.

Incentive compatibility conditions again show that the Agency either chooses its most preferred policy $e^{S B}(\alpha, D)$ or is bound to an effort level independent of the level of damage and of its own preferences. Following this observation, it is straightforward to see that the possible incentive mechanisms still leave discretion when the effort level that the Agency would like to implement, $e^{S B}(\alpha, D)$, is below some threshold $e^{*}$. This is either because $D$ is small enough or because $\alpha$ itself is low enough, i.e. because the Agency's preferences are close enough to Congress' ones.

We can write Congress' problem of choosing an optimal cap $e^{*}$ as:

$$
\begin{gathered}
\left(\mathcal{P}_{R}^{A I}\right): \max _{e^{*}} S-E_{(D, \alpha)}\left((1-e(\alpha, D)) D+\psi(e(\alpha, D))+\left(1-\alpha_{C}\right) R(e(\alpha, D))\right) \\
\text { where } e(\alpha, D)=\min \left\{e^{S B}(\alpha, D), e^{*}\right\} .
\end{gathered}
$$

To get sharp predictions, let us assume again a quadratic disutility function $(\psi(e)=$ $\left.\frac{\lambda e^{2}}{2}\right)$. The optimal cap $e^{*}$ solves: $^{41}$

$$
\int_{\lambda e^{*}}^{\bar{D}}\left(D-\left(2-\alpha_{C}\right) \lambda e^{*}\right)\left(1-G_{\epsilon}\left(2-\frac{D}{\lambda e^{*}}\right)\right) h(D) d D=0 .
$$

We want to understand how "more uncertainty" on the Agency's preferences affects the optimal degree of discretion. As $\epsilon$ increases, the distributions $G_{\epsilon}$ put mass on a greater interval around $\alpha_{R}$. "More uncertainty" on the regulator's preferences can then be modeled as an increase in $\epsilon$. Denote by $e^{*}(\epsilon)$ the optimal cap corresponding to the distribution $G_{\epsilon}$. In particular, we already know from Section 5 that $e^{*}(0)=\frac{D^{*}\left(\alpha_{R}\right)}{\lambda\left(2-\alpha_{R}\right)}$. The following proposition provides an approximation of the optimal cap as $\epsilon$ becomes small.

\footnotetext{
${ }^{41}$ See the Appendix for details.
} 
Proposition 5 Assume that damages are drawn from an exponential distribution on $\mathbb{R}_{+}$ with mean $\mu$. More uncertainty on the Agency's preferences decreases its discretion by a term of second-order magnitude and the following approximation holds

$$
e^{*}(\epsilon)=e^{*}(0)-\frac{2 \lambda\left(e^{*}(0)\right)^{2} \epsilon^{2}}{3 \mu\left(2-\alpha_{C}\right)}+o\left(\epsilon^{2}\right) .
$$

Everything happens as if more uncertainty on the regulator's preferences increases the conflict of interest between Congress and the Agency. The intuition can again be grasped from a careful analysis of the full consequences of downstream moral hazard. Indeed, downstream moral hazard implies that the set of incentive feasible payoffs pairs $(V, U)$ that can be implemented is strictly convex. For each possible realization of the Agency's preferences, the optimal policy that this Agency would implement under full discretion lies on the boundary of that set. However, fluctuations in the Agency's preferences yield "average" payoffs that lie strictly within the interior of that incentive-feasible set. With a uniform distribution of possible preferences for the Agency, the average effort induced is greater than the effort that would have been implemented by an Agency presenting "average" preferences. This is akin to an upward shift in the parameter $\alpha_{R}$, and thus to an increased conflict of interest between Congress and the Agency. By an argument which is by now familiar, the Agency should have less discretion.

The consequences of this result for the dynamics of regulation are interesting. As time goes on, the preferences of the Agency may be revealed at least partially by the past history of its actions. When political uncertainty decreases over time, our model predicts that the Agency should be given more discretion. This also suggests that older agencies should have "on average" more freedom in setting regulatory policies than newly established ones. Of course, this insight is obtained when taking risk as given. In this respect, it goes against Corollary 3 which tends to show that more uncertainty on the nature of the risk at stake leads to more discretion, which means leaving more freedom to newly established regulatory agencies that evolve in environments where there is little knowledge on the nature of this risk. The overall evolution of an Agency's discretion may then result from the tension between, on the one hand, a better knowledge of the risk at stake that decreases its discretion and, on the other hand, a better knowledge of its own preferences which, on the contrary, calls for more discretion.

To conclude, this section shows that the impact of asymmetric information on the Agency's preferences is only second-order compared to the impact of its private expertise on potential harm. This appears as a strong justification for our initial focus on the conflict between Congress and the Agency as coming from its expertise and not from private information on its own agenda. 


\subsection{Strategic Appointment}

The last section has shown how Congress may enact regulations when anticipating changes or at least some uncertainty on the identity of future political principals in the Executive branch. Politics is often more of an ongoing process, with Congress and the Executive reacting each in turn to the other's move and jointly designing the regulatory environment. In this section, we take the alternative view and give the Executive the lead in the appointment process. ${ }^{42}$ The Executive is now able to commit to choose the regulator before Congress decides the level of discretion, even though this choice in practice takes place only after Congress has enacted the regulation. This possibility can be viewed as a reduced form for the complex interactions between the Executive and Legislative branches at the inception of a new regulation. In other words, we no longer consider the Executive and the Agency as a single entity. Instead, we show how such appointments can be used strategically to affect subsequent interactions between Congress and the Agency. More precisely, an Executive with a strong pro-firm bias may strategically appoint a regulator whose preferences are closer to Congress. Accommodating this way Congress' preferences increases the Agency's discretion and favors the firm, in accordance with the Executive's prior objectives. At equilibrium, the Agency's preferences will be chosen somewhere in between those of the Executive and Congress.

To make this point more formally, consider the case where the Executive's preferences $\alpha_{E}$ are more "pro-firm" than Congress, namely $\alpha_{C}<\alpha_{E}<1$. Anticipating the choice of Congress on the level of discretion left to the Agency, the Executive acts as a Stackelberg leader when choosing the regulator.

Proposition 6 Assume that the Executive's preferences $\alpha_{E}$ are more "pro-firm" oriented than those of Congress, i.e. $\alpha_{C}<\alpha_{E}<1$. Then, the Executive chooses a regulator with preferences between those of Congress and its own: $\alpha_{C}<\alpha_{R}<\alpha_{E}$.

This result predicts therefore that regulation reflects, at equilibrium, a subtle compromise between the desires of the different public bodies involved. Choosing a regulator who is a little bit less eager than the Executive to please the firm has only a second-order impact on the Executive's expected payoff when $D$ is low, since the Agency has full discretion in setting up a regulatory policy over that range. However, reducing $\alpha_{R}$ aligns

\footnotetext{
${ }^{42}$ Though they are usually created by the Legislative branch, administrative agencies sit within the Executive branch. As a consequence, the Executive also exercises control over agency decision-making. Most of this influence is channeled through the appointment process since the President is permitted by most originating statutes to appoint the agency's top decision-makers (subject to the approval of the Senate). A typical example is given by nominations at the head of the EPA in the U.S. This Federal Agency is under the control of the Presidency, but it implements environmental regulations enacted by Congress. This process often entails a conflict due to non-congruent views of the administration and Congress, but it is "an accepted part of the political process" (Ashford and Caldart 2008, p. 267).
} 
somewhat the Agency with Congress' objectives and relaxes by a first-order term the cap on possible rewards that Congress imposes once $D$ becomes large.

\subsection{Pro-Firm Congress}

Last, consider the case of an Agency which is less "pro-firm" than Congress. This might arise when the median voter in Congress comes from a district which is much concerned by the firm's industrial activity. The problem is now to induce the Agency to adopt higherpowered incentive regulations that leave more rent to the firm. ${ }^{43}$ There is still a trade-off between rules and discretion, but now it leads to putting a floor on the firm's rewards. Because it now has incentives to pretend that damages are low to induce low-powered regulations, the regulator should have discretion only on the upper tail of the distribution of these damages. On the lower tail instead, a rigid regulation is implemented.

When $\alpha_{R}<\alpha_{C}$, it is straightforward to check that the optimal cut-off $D^{*}\left(\alpha_{R}\right)$ below which the rigid rule binds solves:

$$
E\left(D \mid D \leq D^{*}\left(\alpha_{R}\right)\right)=\psi^{\prime}\left(e^{S B}\left(\alpha_{R}, D^{*}\left(\alpha_{R}\right)\right)\right)+\left(1-\alpha_{C}\right) R^{\prime}\left(e^{S B}\left(\alpha_{R}, D^{*}\left(\alpha_{R}\right)\right)\right)
$$

when $e^{S B}\left(\alpha_{R}, \underline{D}\right) \leq e_{C} \leq e^{S B}\left(\alpha_{R}, \bar{D}\right)$.

Except for this reversal in the nature of the ex ante control and for the associated comparative statics, ${ }^{44}$ most of our results go through. For instance, the Agency should have more discretion when solving the moral hazard problem downstream requires highpowered incentives.

\footnotetext{
${ }^{43}$ When Congress believes that an agency is pursuing regulatory policies that run counter to legislative intent, it can amend the corresponding statute. The Solid Waste Disposal Act (known as the Resource Conservation and Recovery Act) was modified in 1984 in response to a widespread perception in Congress that EPA was not moving swiftly enough to regulate the disposal of hazardous wastes. In a similar vein, Congress amended the Safe Drinking Water Act in 1986 and the Clean Air Act provisions for hazardous air pollutants in 1990 (Ashford and Caldart 2008, p. 258).

${ }^{44}$ For instance, the definition of "front-loading" is now replaced by: a distribution $H_{1}(\cdot)$ is more "frontloaded" than a distribution $H_{2}(\cdot)$ if and only if:

$$
\left.\frac{1}{H_{1}(D)} \int_{\underline{D}}^{D} x h_{1}(x) d x \leq \frac{1}{H_{2}(D)} \int_{\underline{D}}^{D} x h_{2}(x) d x \text { for all } D \in \mathcal{D} \text { (with equality at } \underline{D}\right) \text {. }
$$

This inequality simply means that the conditional expectation of the damages over the lower tail $[\underline{D}, D]$ is always greater with $H_{2}(\cdot)$ than with $H_{1}(\cdot)$. A low report $\hat{D}$ that hurts the firm and goes counter Congress' objectives is thus more likely to arise with $H_{2}(\cdot)$ than with $H_{1}(\cdot)$. Then, one can easily show that the Agency has more discretion with $H_{2}(\cdot)$ than with $H_{1}(\cdot)$.
} 


\section{Conclusion}

This paper has shown how agency problems may propagate along the regulatory hierarchy. Downstream regulation of a limited liability firm in a moral hazard context requires giving up liability rent to induce safety care. However, the "pro-firm" biased Agency and Congress may have conflicting preferences on the amount of this rent. This upstream conflict leads Congress to put ex ante constraints on the incentive rewards that the Agency can use, even though this Agency could tailor the optimal regulation to its expert information. The trade-off between rules and discretion which arises in such contexts depends on economic (most specifically the detailed properties of the distribution of risks and the intensity of the downstream moral hazard problem) as well as various political factors. Optimal regulations may sometimes look like rigid rules making no use of the Agency's expert information. Moreover, uncertainty in the underlying environment, be it on the economic or political side, affects the Agency's optimal discretion. Importantly, any condition that worsens the downstream moral hazard problem with regulated firms exacerbates the endogenous conflict of interest between the Agency and Congress and, ultimately, leads to give less discretion to the Agency.

These results could be extended along several lines. First, we could investigate how ex post devices help to solve the upstream agency problem between Congress and the Agency. The joint use of ex post monitoring devices and ex ante control is a recurring theme of the political science literature. Direct oversights by congressional committees, regulatory budget reviews and costly audits ${ }^{45}$ by specialized agencies such as the General Accounting Office, and fire-alarms by interest groups are all examples of such devices that may help relaxing the Agency's incentive constraints and improve the ex ante trade-off between rules and discretion.

Also, it would be worth investigating the Agency's incentives to acquire information on potential damages in models where the information structure is endogenized. More complex delegation sets that favor discretion for "extreme" values of the damages might be useful to provide such incentives. ${ }^{46}$

Another important extension of our framework would be to consider other agency problems for the regulated sector. Most of the New Economics of Regulation has been developed in a framework where adverse selection downstream generates the regulated firm's informational rent. We conjecture that the lessons of this paper would go through in such an environment. Any kind of asymmetric information downstream is bound to generate a rent/efficiency trade-off. As soon as this trade-off is appreciated differently by the Agency and Congress, the same kind of analysis as the one performed in this paper

\footnotetext{
${ }^{45}$ See Banks (1989) and Banks and Weingast (1992) on this issue.

${ }^{46}$ Szalay (2005).
} 
would apply. Again rules and limited discretion might be quite attractive.

\section{References}

Aghion, P. and J. Tirole (1997), "Formal and Real Authority in Organizations," Journal of Political Economy, 105: 1-29.

Alonso, R. and N. Matousheck (2008), "Optimal Delegation," Review of Economic Studies, 75: 259-293.

Armstrong, M. (1994), "Delegation and Discretion," Discussion Papers in Economics and Econometrics, 9421, University of Southampton.

Armstrong, M. and D. Sappington (2007), "Recent Developments in the Theory of Regulation", Handbook of Industrial Organization, Vol. 3, M. Armstrong and R. Porter eds. North-Holland.

Armstrong, M. and J. Vickers (2008), "A Model of Delegated Project Choice," Mimeo University College of London.

Ashford, N. and C. Caldart (2008), Environmental Law, Policy, and Economics, MIT Press.

Banks, J. (1989), "Agency Budgets, Cost of Information, and Auditing," American Journal of Political Science, 33: 670-699.

Banks, J. and B. Weingast (1992), "The Political Control of Bureaucracies under Asymmetric Information," American Journal of Political Science, 36: 509-524.

Baron, D. (1989), "Regulation and Legislative Choice," Rand Journal of Economics, 19: 467-477.

Baron, D. (2000), "Legislative Organization with Informational Committees," American Journal of Political Sciences, 44: 485-505.

Baron, D. and R. Myerson (1982), "Regulating a Monopolist with Unknown Costs," Econometrica, 50: 911-930.

Bawn, K. (1995), "Political Control versus Expertise: Congressional Choices about Administrative Procedures," American Political Science Review, 89: 62-73.

Besanko, D. and D. Spulber (1993), "Contested Mergers and Equilibrium Antitrust Policy," Journal of Law, Economics and Organization, 9: 1-29. 
Boyer, M. and J.J. Laffont (1999), "Towards a Political Theory of the Emergence of Environmental Incentive Regulation," Rand Journal of Economics, 30: $137-157$.

Epstein, D. and S. O'Halloran (1994), "Administrative Procedures, Information and Agency Discretion," American Journal of Political Science, 38: 697-722.

Epstein, D. and S. O’Halloran (1999), Delegating Powers, Cambridge University Press.

Faure-Grimaud, A. and D. Martimort (2003), "Regulatory Inertia," Rand Journal of Economics, 34: 413-437.

Fiorina, M. (1982), "Legislative Choice of Regulatory Forms: Legal Process or Administrative Process," Public Choice, 39: 33-71.

Heyes, A. and C. Liston-Heyes (2000), "Capping Environmental Liability: The Case of North American Nuclear Power," The Geneva Papers in Risk and Insurance, 25: 196-202.

Hird, J. (1993), "Environmental Policy and Equity: The Case of Superfund," Journal of Policy Analysis and Management, 12: 323-343.

Hird, J. (1994), Superfund: The Political Economy of Environmental Risk, Johns Hopkins University Press.

Hiriart, Y. and D. Martimort (2006), "The Benefits of Extended Liability," Rand Journal of Economics, 37: 562-582.

Holmström, B. (1984), "On the Theory of Delegation," in M. Boyer and R. Kihlstrom (eds), Bayesian Models in Economic Theory, Elsevier Science Publishers B.V.

Hood, C., H. Rothstein and R. Baldwin (2003), The Government of Risk, Oxford University Press.

Horn, M. (1995), The Political Economy of Public Administration, Cambridge University Press.

Huber, J. and C. Shipan (2002), Deliberative Discretion: The Institutional Foundations of Bureaucratic Autonomy, Cambridge University Press.

Huber, J. and C. Shipan (2006), "Politics, Delegation, and Bureaucracy," in B. Weingast and D. Wittman (eds), The Oxford Handbook of Political Economy, Oxford University Press.

Jin, D. and H. Kite-Powell (1999), "On the Optimal Environmental Liability Limit for Marine Oil Transport," Transport Research, 35: 77-100. 
Kovac, E. and T. Mylovanov (2007), "Stochastic Mechanisms in Settings without Monetary Transfers: The Regular Case," forthcoming Journal of Economic Theory.

Laffont, J.J. (1994), "The New Economics of Regulation Ten Years After," Econometrica, 62: 507-537.

Laffont, J.J. (2000), Incentives and Political Economy, Oxford University Press.

Laffont, J.J. and D. Martimort (2002), The Theory of Incentives: The PrincipalAgent Model, Princeton University Press.

Laffont, J.J. and J. Tirole (1993), A Theory of Incentives in Procurement and Regulation, MIT Press.

Lewis, T. and D. Sappington (1988), "Regulating a Monopolist with Unknown Demand and Cost Functions," Rand Journal of Economics, 19: 438-457.

Lewis, T. and D. Sappington (1989), "Inflexible Rules in Incentive Problems," American Economic Review, 79: 69-84.

Martimort, D. and A. Semenov (2006), "Continuity in Mechanism Design without Transfers," Economics Letters, 93: 182-189.

Martimort, D. and A. Semenov (2008), "The Informational Effects of Competition and Collusion in Legislative Politics," Journal of Public Economics, 92: 1541-1563.

Maskin, E. and J. Tirole (1990), "The Principal-Agent Relationship with an Informed Principal: The Case of Private Values," Econometrica, 58: 379409.

Melumad, N. and T. Shibano (1991), "Communication in Settings with no Transfers," Rand Journal of Economics, 22: 173-198.

McCubbins, M., R. Noll and B. Weingast (1987), "Administrative Procedures as Instruments of Political Control," Journal of Law, Economics and Organization, 3: 243-277.

McCubbins, M., R. Noll and B. Weingast (1989), "Structure and Process, Politics and Policy: Administrative Arrangements and the Political Control of Agencies," Virginia Law Review, 75: 431-482.

McCubbins, M. and T. Schwartz (1984), "Congressional Oversight Overlooked: Police Patrol versus Fire Alarms," American Journal of Political Science, 2: $165-179$.

Moe, T. (1989), "The Politics of Bureaucratic Structure," in J. Chubb and P. Peterson (eds), Can the Government Govern, The Brooking Institution. 
Persson, T. and G. Tabellini (1993), "Designing Institutions for Monetary Stability," Carnegie-Rochester Conferences Series on Public Policy, 39: 53-84.

Rogoff, K. (1985), "The Optimal Degree of Commitment to an Intermediate Monetary Target," Quarterly Journal of Economics, 100: 1169-1190.

Shavell, S. (1984), "A Model of the Optimal Use of Liability and Safety Regulation," Rand Journal of Economics, 15: 271-280.

Szalay, D. (2005), "The Economics of Clear Advices and Extreme Opinions," Review of Economic Studies, 72: 1173-1198.

Van Houtven, G. and M. Cropper (1996), "When is a Life too Costly to Save? The Evidence from U.S. Environmental Regulations," Journal of Environmental Economics and Management, 30: 348-368.

Weingast, B and M. Moran (1983), "Bureaucratic Discretion or Congressional Control? Regulatory Policy-Making by the Federal Trade Commission," Journal of Political Economy, 96: 132-163.

Wood, B. and J. Bothe (2004), "Political Transaction Costs and the Politics of Administrative Design," Journal of Politics, 66: 176-202.

\section{Appendix}

- Proofs of Propositions 1, 2 and 3. Those proofs are immediate and thus omitted.

- Proof of Lemma 1. Fix a pair $\left(D, D^{\prime}\right)$ such that $D>D^{\prime}$. From (11), incentive compatibility constraints for $D$ and $D^{\prime}$ respectively imply:

$$
\begin{aligned}
& -D(1-e(D))-\psi(e(D))-(1-\alpha) R(e(D)) \geq-D\left(1-e\left(D^{\prime}\right)\right)-\psi\left(e\left(D^{\prime}\right)\right)-(1-\alpha) R\left(e\left(D^{\prime}\right)\right), \\
& -D^{\prime}\left(1-e\left(D^{\prime}\right)\right)-\psi\left(e\left(D^{\prime}\right)\right)-(1-\alpha) R\left(e\left(D^{\prime}\right)\right) \geq-D^{\prime}(1-e(D))-\psi(e(D))-(1-\alpha) R(e(D)) .
\end{aligned}
$$

Summing these two inequalities yields:

$$
\left(D-D^{\prime}\right)\left(e(D)-e\left(D^{\prime}\right)\right) \geq 0
$$

Hence, $e(\cdot)$ is monotonically increasing and thus almost everywhere differentiable with (12) holding at any differentiability point. At any such point, the first-order condition for (11) writes as (13). (12) is also the local second-order condition for (11).

- Proof of Lemma 2. Lemma 1 shows that $e(\cdot)$ has either flat parts or is equal to $e^{S B}\left(\alpha_{R}, D\right)$. Observing that $e^{S B}\left(\alpha_{R}, D\right)$ is strictly increasing in $D$, continuous mechanisms are such that there exist necessarily two thresholds $D_{*}$ and $D^{*}$ such that (14) holds. 
- Proof of Proposition 4. Using the fact that the optimal mechanism has a cap on the level of effort that can be implemented by the regulator, we can rewrite the maximand in $\left(\mathcal{P}_{R}^{S B}\right)$ as

$$
\begin{gathered}
W_{C}\left(D^{*}\right)=S-\int_{\underline{D}}^{D^{*}}\left(D\left(1-e^{S B}\left(\alpha_{R}, D\right)\right)+\psi\left(e^{S B}\left(\alpha_{R}, D\right)\right)+\left(1-\alpha_{C}\right) R\left(e^{S B}\left(\alpha_{R}, D\right)\right)\right) h(D) d D \\
-\int_{D^{*}}^{\bar{D}}\left(D\left(1-e^{S B}\left(\alpha_{R}, D^{*}\right)\right)+\psi\left(e^{S B}\left(\alpha_{R}, D^{*}\right)\right)+\left(1-\alpha_{C}\right) R\left(e^{S B}\left(\alpha_{R}, D^{*}\right)\right)\right) h(D) d D .
\end{gathered}
$$

Note that

$\dot{W}_{C}\left(D^{*}\right)=\frac{\partial e^{S B}}{\partial D^{*}}\left(\alpha_{R}, D^{*}\right) \int_{D^{*}}^{\bar{D}}\left(D-\psi^{\prime}\left(e^{S B}\left(\alpha_{R}, D^{*}\right)\right)-\left(1-\alpha_{C}\right) R^{\prime}\left(e^{S B}\left(\alpha_{R}, D^{*}\right)\right)\right) h(D) d D$ where $\frac{\partial e^{S B}}{\partial D^{*}}\left(\alpha_{R}, D^{*}\right)=\frac{1}{\psi^{\prime \prime}\left(e^{S B}\left(\alpha_{R}, D^{*}\right)\right)+\left(1-\alpha_{R}\right) R^{\prime \prime}\left(e^{S B}\left(\alpha_{R}, D^{*}\right)\right.}>0$ with

$$
\begin{gathered}
\ddot{W}_{C}\left(D^{*}\right)=\frac{\partial e^{S B}}{\partial D^{*}}\left(\alpha_{R}, D^{*}\right)\left(\alpha_{R}-\alpha_{C}\right) R^{\prime}\left(e^{S B}\left(\alpha_{R}, D^{*}\right)\right) h\left(D^{*}\right) \\
+\frac{\partial^{2} e^{S B}}{\partial D^{* 2}}\left(\alpha_{R}, D^{*}\right) \int_{D^{*}}^{\bar{D}}\left(D-\psi^{\prime}\left(e^{S B}\left(\alpha_{R}, D^{*}\right)\right)-\left(1-\alpha_{C}\right) R^{\prime}\left(e^{S B}\left(\alpha_{R}, D^{*}\right)\right)\right) h(D) d D \\
-\left(\frac{\partial e^{S B}}{\partial D^{*}}\left(\alpha_{R}, D^{*}\right)\right)^{2}\left(\psi^{\prime \prime}\left(e^{S B}\left(\alpha_{R}, D^{*}\right)\right)+\left(1-\alpha_{C}\right) R^{\prime \prime}\left(e^{S B}\left(\alpha_{R}, D^{*}\right)\right)\left(1-H\left(D^{*}\right)\right) .\right.
\end{gathered}
$$

Optimizing $\left(\mathcal{P}_{R}^{S B}\right)$ with respect to $D^{*}$ yields the following first-order condition for an interior solution $D^{*}\left(\alpha_{R}\right)$ :

$\dot{W}_{C}\left(D^{*}\left(\alpha_{R}\right)\right)=0 \Leftrightarrow \int_{D^{*}\left(\alpha_{R}\right)}^{\bar{D}}\left(D-\psi^{\prime}\left(e^{S B}\left(\alpha_{R}, D^{*}\right)\right)-\left(1-\alpha_{C}\right) R^{\prime}\left(e^{S B}\left(\alpha_{R}, D^{*}\left(\alpha_{R}\right)\right)\right)\right) h(D) d D=0$.

Therefore, an interior $D^{*}\left(\alpha_{R}\right) \in(\underline{D}, \bar{D})$ solves (15). Note that $\dot{W}_{C}(\underline{D}) \geq 0$ when $\int_{\underline{D}}^{\bar{D}}\left(D-\psi^{\prime}\left(e^{S B}\left(\alpha_{R}, \underline{D}\right)\right)-\left(1-\alpha_{C}\right) R^{\prime}\left(e^{S B}\left(\alpha_{R}, \underline{D}\right)\right)\right) h(D) d D \geq 0$ or, taking into account the definition of $e_{C}$ given in $(10)$, when $e^{S B}\left(\alpha_{R}, \underline{D}\right) \leq e_{C}$. Moreover, $\dot{W}_{C}(\bar{D})=0$ so that $\bar{D}$ satisfies the first-order condition $\left(\right.$ A.1) but $\ddot{W}_{C}(\bar{D})>0$ (so that $\dot{W}_{C}(\bar{D})<0$ in a left-neighborhood of $\bar{D}$ ) and the second-order condition for optimality does not hold at that point. Putting together these two facts, there always exists an interior solution to (15) that satisfies the second-order condition.

In fact, this interior solution to (15) is unique. To see why, denote respectively the leftand right-hand sides of $(15)$ as $A\left(D^{*}\right)=E\left(\tilde{D} \mid \tilde{D} \geq D^{*}\right)=D^{*}+\frac{1}{1-H\left(D^{*}\right)} \int_{D^{*}}^{\bar{D}}(1-H(x)) d x$ and $B\left(D^{*}\right)=\psi^{\prime}\left(e^{S B}\left(\alpha_{R}, D^{*}\right)\right)+\left(1-\alpha_{C}\right) R^{\prime}\left(e^{S B}\left(\alpha_{R}, D^{*}\right)\right)$.

First, observe that

$$
\dot{A}\left(D^{*}\right)=\frac{h\left(D^{*}\right)}{\left(1-H\left(D^{*}\right)\right)^{2}} \int_{D^{*}}^{\bar{D}}(1-H(x)) d x \leq 1 \Leftrightarrow \varphi\left(D^{*}\right) \geq 0
$$


where $\varphi\left(D^{*}\right)=\frac{\left(1-H\left(D^{*}\right)\right)^{2}}{h\left(D^{*}\right)}-\int_{D^{*}}^{\bar{D}}(1-H(x)) d x$. Note that $\dot{\varphi}\left(D^{*}\right)=\left(1-H\left(D^{*}\right)\right) \frac{d}{d D^{*}}\left(\frac{1-H\left(D^{*}\right)}{h\left(D^{*}\right)}\right) \leq$ 0 and thus $\varphi\left(D^{*}\right) \geq \varphi(\bar{D})=0$ for all $D \in \mathcal{D}$.

Second, observe also that, since $\alpha_{R}>\alpha_{C}$,

$$
\begin{aligned}
\dot{B}\left(D^{*}\right) & =\frac{\partial e^{S B}}{\partial D^{*}}\left(\alpha_{R}, D^{*}\right)\left(\psi^{\prime \prime}\left(e^{S B}\left(\alpha_{R}, D^{*}\right)\right)+\left(1-\alpha_{C}\right) R^{\prime \prime}\left(e^{S B}\left(\alpha_{R}, D^{*}\right)\right)\right. \\
& =\frac{\psi^{\prime \prime}\left(e^{S B}\left(\alpha_{R}, D^{*}\right)\right)+\left(1-\alpha_{C}\right) R^{\prime \prime}\left(e^{S B}\left(\alpha_{R}, D^{*}\right)\right)}{\psi^{\prime \prime}\left(e^{S B}\left(\alpha_{R}, D^{*}\right)\right)+\left(1-\alpha_{R}\right) R^{\prime \prime}\left(e^{S B}\left(\alpha_{R}, D^{*}\right)\right)}>1 .
\end{aligned}
$$

Hence, $\dot{A}\left(D^{*}\right)<\dot{B}\left(D^{*}\right)$ which in passing shows that $W_{C}(\cdot)$ is quasi-concave. Since $A(\underline{D}) \geq B(\underline{D})$ when $e^{S B}\left(\alpha_{R}, \underline{D}\right) \leq e_{C}$ and $A(\bar{D})<B(\bar{D})$ since $e^{S B}\left(\alpha_{R}, \bar{D}\right)>e^{S B}\left(\alpha_{C}, \bar{D}\right)$, $D^{*}\left(\alpha_{R}\right)$ such that $A\left(D^{*}\left(\alpha_{R}\right)\right)=B\left(D^{*}\left(\alpha_{R}\right)\right)$ is uniquely defined.

Since $A\left(D^{*}\right)<\bar{D}$, we have also $e^{S B}\left(\alpha_{R}, D^{*}\left(\alpha_{R}\right)\right)<e^{S B}\left(\alpha_{C}, \bar{D}\right)$ as shown on Figure 1 .

Rigid rule. When $e^{S B}\left(\alpha_{R}, \underline{D}\right)>e_{C}, \dot{W}_{C}(\underline{D})<0$, and a rigid rule at $e_{C}$ is optimal.

Partial discretion. Full discretion never arises since $D^{*}=\bar{D}$, although it solves (A.1) never satisfies the second-order condition since $\ddot{W}_{C}(\bar{D})>0$.

Suboptimality of a floor. Suppose now that the Agency adds a floor at $e^{S B}\left(\alpha_{R}, D^{* *}\right)$ with $D^{* *}<D^{*}$. We can now rewrite Congress's objective as:

$$
\begin{gathered}
W_{C}\left(D^{* *}, D^{*}\right)=S-\int_{D^{* *}}^{D^{*}}\left(D\left(1-e^{S B}\left(\alpha_{R}, D\right)\right)+\psi\left(e^{S B}\left(\alpha_{R}, D\right)\right)+\left(1-\alpha_{C}\right) R\left(e^{S B}\left(\alpha_{R}, D\right)\right)\right) h(D) d D \\
-\int_{D^{*}}^{\bar{D}}\left(D\left(1-e^{S B}\left(\alpha_{R}, D^{*}\right)\right)+\psi\left(e^{S B}\left(\alpha_{R}, D^{*}\right)\right)+\left(1-\alpha_{C}\right) R\left(e^{S B}\left(\alpha_{R}, D^{*}\right)\right)\right) h(D) d D \\
-\int_{\underline{D}}^{D^{* *}}\left(D\left(1-e^{S B}\left(\alpha_{R}, D^{* *}\right)\right)+\psi\left(e^{S B}\left(\alpha_{R}, D^{* *}\right)\right)+\left(1-\alpha_{C}\right) R\left(e^{S B}\left(\alpha_{R}, D^{* *}\right)\right)\right) h(D) d D .
\end{gathered}
$$

Observe then that:

$$
\frac{\partial W_{C}}{\partial D^{* *}}\left(D^{* *}, D^{*}\right)=\frac{\partial e^{S B}}{\partial D^{* *}}\left(\alpha_{R}, D^{* *}\right) \int_{\underline{D}}^{D^{* *}}\left(D-\psi^{\prime}\left(e^{S B}\left(\alpha_{R}, D^{* *}\right)\right)-\left(1-\alpha_{C}\right) R^{\prime}\left(e^{S B}\left(\alpha_{R}, D^{* *}\right)\right)\right) h(D) d D
$$

so that $\frac{\partial W_{C}}{\partial D^{* *}}\left(\underline{D}, D^{*}\right)=0$ and

$$
\begin{gathered}
\frac{\partial^{2} W_{C}}{\partial\left(D^{* *}\right)^{2}}\left(\underline{D}, D^{*}\right)=\frac{\partial e^{S B}}{\partial D^{* *}}\left(\alpha_{R}, \underline{D}\right)\left(\alpha_{C}-\alpha_{R}\right) R^{\prime}\left(e^{S B}\left(\alpha_{R}, \underline{D}\right)\right) h(\underline{D}) \\
-\left(\frac{\partial e^{S B}}{\partial D^{* *}}\left(\alpha_{R}, \underline{D}\right)\right)^{2}\left(\psi^{\prime \prime}\left(e^{S B}\left(\alpha_{R}, D^{* *}\right)\right)+\left(1-\alpha_{C}\right) R^{\prime \prime}\left(e^{S B}\left(\alpha_{R}, D^{* *}\right)\right)\right) \leq 0 .
\end{gathered}
$$

Hence, $D^{* *}=\underline{D}$ is optimal. 
- Proof of Corollary 1. From (A.2), we deduce that $A(D)-D$ is decreasing. The solution $D^{*}\left(\alpha_{R}\right)$ to $(16)$ which writes as $A\left(D^{*}\left(\alpha_{R}\right)\right)-D^{*}\left(\alpha_{R}\right)=\frac{\Delta \alpha}{2-\alpha_{R}} D^{*}\left(\alpha_{R}\right)$ decreases with $\Delta \alpha$.

- Proof of Corollary 2. Suppose that $H_{1}(\cdot)$ is more front-loaded than $H_{2}(\cdot)$, i.e. (17) holds. Denote by $D_{i}^{*}\left(\alpha_{R}\right)$ the optimal cap for distribution $H_{i}(\cdot)$. From $(16)$, we have then:

$$
\frac{1}{\left.1-H_{2}\left(D_{1}^{*}\left(\alpha_{R}\right)\right)\right)} \int_{D_{1}^{*}\left(\alpha_{R}\right)}^{\bar{D}} x h_{2}(x) d x \geq \psi^{\prime}\left(e_{R}\left(D_{1}^{*}\left(\alpha_{R}\right)\right)\right)+\left(1-\alpha_{C}\right) R^{\prime}\left(e_{R}\left(D_{1}^{*}\left(\alpha_{R}\right)\right)\right) .
$$

Using the fact that $W_{C}(\cdot)$ (when expectations are computed with $H_{2}(\cdot)$ ) is quasi-concave, we have necessarily $D_{1}^{*}\left(\alpha_{R}\right) \geq D_{2}^{*}\left(\alpha_{R}\right)$.

- Proof of Corollary 3. First observe that $D_{k}^{*}\left(\alpha_{R}\right)$ and $D^{*}\left(\alpha_{R}\right)$ solve

$$
D_{k}^{*}\left(\alpha_{R}\right)=\mu_{k} \frac{2-\alpha_{R}}{\Delta \alpha} \text { and } \frac{E_{k}\left(\mu_{k} \exp \left(-\frac{D^{*}\left(\alpha_{R}\right)}{\mu_{k}}\right)\right)}{E_{k}\left(\exp \left(-\frac{D^{*}\left(\alpha_{R}\right)}{\mu_{k}}\right)\right)}=\frac{\Delta \alpha}{2-\alpha_{R}} D^{*}\left(\alpha_{R}\right)
$$

Because $\exp \left(-\frac{D^{*}}{\mu}\right)$ and $\mu$ are both increasing in $\mu$, they both covary in the same direction which implies:

$$
\frac{\Delta \alpha}{2-\alpha_{R}} D^{*}\left(\alpha_{R}\right)=\frac{E_{k}\left(\mu_{k} \exp \left(-\frac{D^{*}\left(\alpha_{R}\right)}{\mu_{k}}\right)\right)}{E_{k}\left(\exp \left(-\frac{D^{*}\left(\alpha_{R}\right)}{\mu_{k}}\right)\right)} \geq E_{k}\left(\mu_{k}\right)=\frac{\Delta \alpha}{2-\alpha_{R}} E_{k}\left(D_{k}^{*}\left(\alpha_{R}\right)\right) .
$$

This yields (18).

- Proof of Corollary 4. For the case of a quadratic disutility function, $\psi(e)=\frac{\lambda e^{2}}{2}$ with $\lambda$ large enough so that effort remains in $(0,1)$, we obtain

$$
e^{S B}\left(\alpha_{R}, D\right)=\frac{D-\left(1-\alpha_{R}\right) \lambda \eta}{\lambda\left(2-\alpha_{R}\right)}
$$

which remains positive when

$$
\eta<\frac{\underline{D}}{\lambda\left(1-\alpha_{R}\right)} .
$$

The optimal level of discretion now satisfies:

$$
E\left(D \mid D \geq D^{*}\left(\alpha_{R}\right)\right)-D^{*}\left(\alpha_{R}\right)=\frac{\Delta \alpha}{2-\alpha_{R}}\left(D^{*}\left(\alpha_{R}\right)+\lambda \eta\right)
$$

Since $A(D)-D$ is decreasing, the solution $D^{*}\left(\alpha_{R}\right)$ to (A.5) which writes now as $A\left(D^{*}\left(\alpha_{R}\right)\right)-D^{*}\left(\alpha_{R}\right)=\frac{\Delta \alpha}{2-\alpha_{R}}\left(D^{*}\left(\alpha_{R}\right)+\lambda \eta\right)$ decreases with $\eta$.

- Proof of Corollary 5. Everything happens as if the formula for the second-best effort and the optimal level of discretion were the same as in (A.3) and (A.5), with $\eta$ 
being preceded by a sign -. Moreover, state 2 has a positive probability as long as $\eta$ still satisfies (A.4).

- Proof of Corollary 6. Still in the quadratic case, the optimal level of discretion now solves:

$$
E\left(D \mid D \geq D^{*}\left(\alpha_{R}\right)\right)-D^{*}\left(\alpha_{R}\right)=\frac{\Delta \alpha}{2-\alpha_{R}}\left(D^{*}\left(\alpha_{R}\right)+\frac{\lambda \eta}{1-\theta}\right)
$$

which is similar to (A.5) when damages have been scaled down by $1-\theta$ to take into account the fact that an accident only occurs when monitoring fails. Now effort remains positive when $\eta<\frac{\underline{D}}{\lambda\left(1-\alpha_{R}\right)(1-\theta)}$.

- Proof of Proposition 5. In this context, incentive compatibility constraints necessary to induce truthtelling now become:

$$
(\alpha, D) \in \underset{(\hat{\alpha}, \hat{D})}{\arg \max } S-(1-e((\hat{\alpha}, \hat{D})) D-\psi(e(\hat{\alpha}, \hat{D}))-(1-\alpha) R(e(\hat{\alpha}, \hat{D})) .
$$

Standard revealed preferences arguments lead to the following Lemma whose proof is similar to that of Lemma 1 and is thus omitted.

Lemma 3 Any incentive compatible mechanism $\{e(\hat{\alpha}, \hat{D})\}_{\{\hat{\alpha} \in[\alpha, \bar{\alpha}], \hat{D} \in[D, \bar{D}]\}}$ is such that $e(\cdot)$ is monotonically increasing in $\alpha$ and $D$ and is thus almost everywhere differentiable with, at any differentiable point,

$$
\begin{gathered}
\frac{\partial e}{\partial \alpha}(\alpha, D) \geq 0 \text { and } \frac{\partial e}{\partial D}(\alpha, D) \geq 0 \\
\frac{\partial e}{\partial \alpha}(\alpha, D)\left(D-\psi^{\prime}(e(\alpha, D))-(1-\alpha) R^{\prime}(e(\alpha, D))\right)=0, \\
\frac{\partial e}{\partial D}(\alpha, D)\left(D-\psi^{\prime}(e(\alpha, D))-(1-\alpha) R^{\prime}(e(\alpha, D))\right)=0 .
\end{gathered}
$$

Hence, (A.8) and (A.9) when taken altogether again show that the Agency either chooses its most preferred policy $e^{S B}(\alpha, D)$ or is forced to choose an effort level independent of the level of damage and of its own preferences. Mechanisms with a cap on effort levels are thus of the form $e(\alpha, D)=\min \left\{e^{S B}(\alpha, D), e^{*}\right\}$.

Optimality condition. We can rewrite the maximand $W_{C}\left(e^{*}\right)$ in $\left(\mathcal{P}_{R}^{A I}\right)$ as

$$
\begin{gathered}
\left.W_{C}\left(e^{*}\right)=S-\int_{\bar{\Omega}} D\left(1-e^{S B}(\alpha, D)\right)+\psi\left(e^{S B}(\alpha, D)\right)+\left(1-\alpha_{C}\right) R\left(e^{S B}(\alpha, D)\right)\right) d H(D) d G_{\epsilon}(\alpha) \\
\left.-\int_{\Omega} D\left(1-e^{*}\right)+\psi\left(e^{*}\right)+\left(1-\alpha_{C}\right) R\left(e^{*}\right)\right) d H(D) d G_{\epsilon}(\alpha)
\end{gathered}
$$

where

$$
\Omega=\left\{(\alpha, D) \in\left[\alpha_{C}, 1\right] \times \mathcal{D} \text { such that } D-\psi^{\prime}\left(e^{*}\right)-(1-\alpha) R^{\prime}\left(e^{*}\right) \geq 0\right\}
$$


is the set of pairs $(\alpha, D)$ where the regulatory cap on effort binds and

$$
\bar{\Omega}=\left\{(\alpha, D) \in\left[\alpha_{C}, 1\right] \times \mathcal{D} \text { such that } D-\psi^{\prime}\left(e^{*}\right)-(1-\alpha) R^{\prime}\left(e^{*}\right)<0\right\}
$$

is the set of pairs $(\alpha, D)$ where this cap does not bind.

Using that $\psi(e)=\frac{\lambda e^{2}}{2}$, we get $e^{S B}(\alpha, D)=\frac{D}{\lambda(2-\alpha)}$ so that

$\Omega=\left\{(\alpha, D) \in\left[\alpha_{C}, 1\right] \times \mathcal{D}\right.$ and $\left.2-\alpha \leq \frac{D}{\lambda e^{*}}\right\}$ and $\bar{\Omega}=\left\{(\alpha, D) \in\left[\alpha_{C}, 1\right] \times \mathcal{D}\right.$ and $\left.2-\alpha>\frac{D}{\lambda e^{*}}\right\}$

Observe then that:

$$
\begin{aligned}
W_{C}\left(e^{*}\right) & =S+\int_{\bar{\Omega}}\left(-D+\frac{D^{2}}{\lambda(2-\alpha)}\left(1-\frac{2-\alpha_{C}}{2(2-\alpha)}\right)\right) h(D) d D d G_{\epsilon}(\alpha) \\
& +\int_{\Omega}\left(-D\left(1-e^{*}\right)-\frac{\lambda\left(e^{*}\right)^{2}}{2}\left(2-\alpha_{C}\right)\right) h(D) d D d G_{\epsilon}(\alpha) .
\end{aligned}
$$

We can rewrite this expression as:

$$
\begin{aligned}
W_{C}\left(e^{*}\right) & =S+\int_{\underline{D}}^{\bar{D}}\left(-D+\int_{\alpha_{C}}^{\min \left\{2-\frac{D}{\lambda e^{*}} ; 1\right\}} \frac{D^{2}}{\lambda(2-\alpha)}\left(1-\frac{2-\alpha_{C}}{2(2-\alpha)}\right) d G_{\epsilon}(\alpha)\right) h(D) d D \\
& +\int_{\underline{D}}^{\bar{D}}\left(-D+\int_{\min \left\{2-\frac{D}{\lambda e^{*}} ; 1\right\}}^{1}\left(D e^{*}-\frac{\lambda\left(e^{*}\right)^{2}}{2}\left(2-\alpha_{C}\right)\right) d G_{\epsilon}(\alpha)\right) h(D) d D .
\end{aligned}
$$

Developing the first of these integrals (for the relevant case where $\bar{D}>\lambda e^{*}$ ) yields:

$$
\begin{gathered}
W_{C}\left(e^{*}\right)=S+\int_{\underline{D}}^{\lambda e^{*}}\left(-D+\int_{\alpha_{C}}^{1} \frac{D^{2}}{\lambda(2-\alpha)}\left(1-\frac{2-\alpha_{C}}{2(2-\alpha)}\right) d G_{\epsilon}(\alpha)\right) h(D) d D \\
+\int_{\lambda e^{*}}^{\bar{D}}\left(-D+\int_{\alpha_{C}}^{2-\frac{D}{\lambda e^{*}}} \frac{D^{2}}{\lambda(2-\alpha)}\left(1-\frac{2-\alpha_{C}}{2(2-\alpha)}\right) d G_{\epsilon}(\alpha)\right) h(D) d D \\
+\int_{\lambda e^{*}}^{\bar{D}}\left(-D+\left(D e^{*}-\frac{\lambda\left(e^{*}\right)^{2}}{2}\left(2-\alpha_{C}\right)\right)\left(1-G_{\epsilon}\left(2-\frac{D}{\lambda e^{*}}\right)\right)\right) h(D) d D .
\end{gathered}
$$

We can now differentiate this expression with respect to $e^{*}$ to obtain the optimal regulatory cap: ${ }^{47}$

$$
\dot{W}_{C}\left(e^{*}\right)=0 \Leftrightarrow \int_{\lambda e^{*}}^{\bar{D}}\left(D-\left(2-\alpha_{C}\right) \lambda e^{*}\right)\left(1-G_{\epsilon}\left(2-\frac{D}{\lambda e^{*}}\right)\right) h(D) d D=0
$$

so that the optimal cap $e^{*}$ is given by condition (24).

\footnotetext{
${ }^{47}$ Note that the quasi-concavity of the objective is guaranteed when $\epsilon$ is small enough by the fact that this property already holds at $\epsilon=0$. (See the Proof of Proposition 4 above).
} 
Approximation. Using the expression of $G_{\epsilon}$ given in the text, we obtain that $e^{*}(\epsilon)$ solves the following equation:

$$
\begin{gathered}
f\left(e^{*}(\epsilon), \epsilon\right)=0=\int_{\left(2-\alpha_{R}-\epsilon\right) \lambda e^{*}(\epsilon)}^{\left(2-\alpha_{R}+\epsilon\right) \lambda e^{*}(\epsilon)}\left(D-\left(2-\alpha_{C}\right) \lambda e^{*}(\epsilon)\right)\left(1-\frac{2-\frac{D}{\lambda e^{*}(\epsilon)}-\alpha_{R}+\epsilon}{2 \epsilon}\right) h(D) d D \\
\quad+\int_{\left(2-\alpha_{R}+\epsilon\right) \lambda e^{*}(\epsilon)}^{\bar{D}}\left(D-\left(2-\alpha_{C}\right) \lambda e^{*}(\epsilon)\right) h(D) d D .
\end{gathered}
$$

For the quadratic disutility function $\psi(e)=\frac{\lambda e^{2}}{2}$, we have $e^{*}(0)=e^{S B}\left(\alpha_{R}, D^{*}\left(\alpha_{R}\right)\right)=$ $\frac{D^{*}\left(\alpha_{R}\right)}{\lambda\left(2-\alpha_{R}\right)}$ where $D^{*}\left(\alpha_{R}\right)$ solves (16). In particular, for an exponential distribution 1 $H(D)=\exp \left(-\frac{D}{\mu}\right)\left(\right.$ with density $h(D)=\frac{1}{\mu} \exp \left(-\frac{D}{\mu}\right)$ ) we have $D^{*}\left(\alpha_{R}\right)=\mu \frac{2-\alpha_{R}}{\Delta \alpha}$ and

$$
e^{*}(0)=\frac{\mu}{\lambda \Delta \alpha}
$$

We look for a second-order approximation of $e^{*}(\epsilon)$ as:

$$
e^{*}(\epsilon)=e^{*}(0)+\alpha \epsilon+\frac{\beta}{2} \epsilon^{2}+o\left(\epsilon^{2}\right)
$$

Making second-order Taylor expansions of the condition $f\left(e^{*}(\epsilon), \epsilon\right)=0$, we can find $(\alpha, \beta)$ as solutions to the following system:

$$
f_{e}\left(e^{*}(0), 0\right) \alpha+f_{\epsilon}\left(e^{*}(0), 0\right)=0
$$

and

$$
f_{e}\left(e^{*}(0), 0\right) \beta+f_{\epsilon \epsilon}\left(e^{*}(0), 0\right)+f_{e e}\left(e^{*}(0), 0\right) \alpha^{2}+2 f_{e \epsilon}\left(e^{*}(0), 0\right) \alpha=0 .
$$

First, observe that:

$$
f_{e}\left(e^{*}, 0\right)=-\lambda\left(2-\alpha_{C}\right)\left(1-H\left(\left(2-\alpha_{R}\right) \lambda e^{*}\right)\right) \neq 0
$$

To compute the other derivatives, let us first consider the first integral on the righthand side of (A.11):

$$
g\left(e^{*}, \epsilon\right)=\int_{\left(2-\alpha_{R}-\epsilon\right) \lambda e^{*}}^{\left(2-\alpha_{R}+\epsilon\right) \lambda e^{*}}\left(D-\left(2-\alpha_{C}\right) \lambda e^{*}\right)\left(1-\frac{2-\frac{D}{\lambda e^{*}}-\alpha_{R}+\epsilon}{2 \epsilon}\right) h(D) d D .
$$

Introducing the change of variables $D=\left(2-\alpha_{R}+\epsilon x\right) \lambda e^{*}$ with $d D=\epsilon \lambda e^{*} d x$, we can rewrite

$$
g\left(e^{*}, \epsilon\right)=\left(\lambda e^{*}\right)^{2} \int_{-1}^{1}(-\Delta \alpha+\epsilon x) \epsilon\left(\frac{1+x}{2}\right) h\left(\left(2-\alpha_{R}+\epsilon x\right) \lambda e^{*}\right) d x .
$$


With this expression, it becomes easy to compute:

$$
g_{\epsilon}\left(e^{*}, 0\right)=-\left(\lambda e^{*}\right)^{2} \Delta \alpha h\left(\left(2-\alpha_{R}\right) \lambda e^{*}\right) \int_{-1}^{1}\left(\frac{1+x}{2}\right) d x=-\left(\lambda e^{*}\right)^{2} \Delta \alpha h\left(\left(2-\alpha_{R}\right) \lambda e^{*}\right) .
$$

Also, we get:

$$
g_{\epsilon \epsilon}\left(e^{*}, 0\right)=\left(\lambda e^{*}\right)^{2}\left(-\lambda e^{*} \Delta \alpha h^{\prime}\left(\left(2-\alpha_{R}\right) \lambda e^{*}\right)+h\left(\left(2-\alpha_{R}\right) \lambda e^{*}\right)\right)\left(\int_{-1}^{1} x(1+x) d x\right)
$$

where $\int_{-1}^{1} x(1+x) d x=\frac{2}{3}$.

Consider now the second integral on the right-hand side of (A.11):

$$
i\left(e^{*}, \epsilon\right)=\int_{\left(2-\alpha_{R}+\epsilon\right) \lambda e^{*}}^{\bar{D}}\left(D-\left(2-\alpha_{C}\right) \lambda e^{*}\right) h(D) d D .
$$

Differentiating, we get

$$
i_{\epsilon}\left(e^{*}, 0\right)=\left(\lambda e^{*}\right)^{2} \Delta \alpha h\left(\left(2-\alpha_{R}\right) \lambda e^{*}\right)=-g_{\epsilon}\left(e^{*}, 0\right) .
$$

Therefore, $f_{\epsilon}\left(e^{*}, 0\right)=g_{\epsilon}\left(e^{*}, 0\right)+i_{\epsilon}\left(e^{*}, 0\right)=0$ and thus, inserting into (A.13), we get:

$$
\alpha=0 .
$$

Differentiating one more time

$$
i_{\epsilon \epsilon}\left(e^{*}, 0\right)=\left(\lambda e^{*}\right)^{2}\left(\lambda e^{*} \Delta \alpha h^{\prime}\left(\left(2-\alpha_{R}\right) \lambda e^{*}\right)-h\left(\left(2-\alpha_{R}\right) \lambda e^{*}\right)\right) .
$$

This leads to

$$
f_{\epsilon \epsilon}\left(e^{*}, 0\right)=g_{\epsilon \epsilon}\left(e^{*}, 0\right)+i_{\epsilon \epsilon}\left(e^{*}, 0\right)=\frac{1}{3}\left(\lambda e^{*}\right)^{2}\left(\lambda e^{*} \Delta \alpha h^{\prime}\left(\left(2-\alpha_{R}\right) \lambda e^{*}\right)-h\left(\left(2-\alpha_{R}\right) \lambda e^{*}\right)\right) .
$$

Using (A.14) and the result above in (A.17), we get:

$$
\beta=-\frac{f_{\epsilon \epsilon}\left(e^{*}(0), 0\right)}{f_{e}\left(e^{*}(0), 0\right)}=\frac{\left(\lambda e^{*}(0)\right)^{2}\left(\lambda e^{*}(0) \Delta \alpha h^{\prime}\left(\left(2-\alpha_{R}\right) \lambda e^{*}(0)\right)-h\left(\left(2-\alpha_{R}\right) \lambda e^{*}(0)\right)\right)}{3 \lambda\left(2-\alpha_{C}\right)\left(1-H\left(\left(2-\alpha_{R}\right) \lambda e^{*}(0)\right)\right)} .
$$

Taking into account (A.12) and the fact that we have an exponential distribution 1 $H(D)=\exp \left(-\frac{D}{\mu}\right)$ (with density $h(D)=\frac{1}{\mu} \exp \left(-\frac{D}{\mu}\right)$ ), we finally obtain the secondorder approximation in (25).

- Proof of Proposition 6. Formally, the Executive looks for an optimal preference parameter of the Agency $\alpha_{R}$ which solves the following problem:

$$
\begin{gathered}
\left(\mathcal{P}_{R}^{\alpha_{R}}\right): \quad \max _{\alpha_{R}} S-E_{D}\left(D\left(1-e\left(\alpha_{R}, D\right)\right)+\psi\left(e\left(\alpha_{R}\right)\right)+\left(1-\alpha_{E}\right) R\left(e\left(\alpha_{R}, D\right)\right)\right) \\
\text { where } e\left(\alpha_{R}, D\right)=\min \left\{e^{S B}\left(\alpha_{R}, D\right), e^{S B}\left(\alpha_{R}, D^{*}\left(\alpha_{R}\right)\right)\right\} .
\end{gathered}
$$


Denoting by $W_{E}\left(\alpha_{R}\right)$ the maximand above, it is straightforward to check that:

$$
\begin{gathered}
\dot{W}_{E}\left(\alpha_{R}\right)=\left(\alpha_{E}-\alpha_{R}\right) \int_{\underline{D}}^{D^{*}\left(\alpha_{R}\right)} R^{\prime}\left(e^{S B}\left(\alpha_{R}, D\right)\right) \frac{\partial e^{S B}}{\partial \alpha_{R}}\left(\alpha_{R}, D\right) h(D) d D \\
+\left(\alpha_{E}-\alpha_{C}\right)\left(1-H\left(D^{*}\left(\alpha_{R}\right)\right)\right) R^{\prime}\left(e^{S B}\left(\alpha_{R}, D^{*}\left(\alpha_{R}\right)\right)\right) \frac{\partial e^{S B}}{\partial D}\left(\alpha_{R}, D^{*}\left(\alpha_{R}\right)\right) \dot{D}^{*}\left(\alpha_{R}\right) .
\end{gathered}
$$

When evaluating this derivative at $\alpha_{R}=\alpha_{E}$, i.e., at the point where the regulator's preferences are aligned with those of the Executive, we obtain:

$$
\dot{W}_{E}\left(\alpha_{E}\right)=\left(\alpha_{E}-\alpha_{C}\right)\left(1-H\left(D^{*}\left(\alpha_{E}\right)\right)\right) R^{\prime}\left(e^{S B}\left(\alpha_{E}, D^{*}\left(\alpha_{E}\right)\right)\right) \frac{\partial e^{S B}}{\partial D}\left(\alpha_{E}, D^{*}\left(\alpha_{E}\right)\right) \dot{D}^{*}\left(\alpha_{E}\right) .
$$

Observe now that first, $\dot{D}^{*}<0$ when $\alpha_{E}>\alpha_{C}$, i.e. the Agency has less discretion when its preferences further diverge from those of Congress; second, $\frac{\partial e^{S B}}{\partial D}>0$, i.e. a higher harm calls for higher levels of prevention. Hence, we have $\dot{W}_{E}\left(\alpha_{E}\right)<0$. Reducing $\alpha_{R}$ below $\alpha_{E}$ always improves the Executive's expected payoff.

Similarly, evaluating $\dot{W}_{E}\left(\alpha_{R}\right)$ at $\alpha_{R}=\alpha_{C}$ and taking into account that $D^{*}\left(\alpha_{C}\right)=\bar{D}$, we find $\dot{W}_{E}\left(\alpha_{C}\right)=\left(\alpha_{E}-\alpha_{C}\right) \int_{\underline{D}}^{\bar{D}} R^{\prime}\left(e^{S B}\left(\alpha_{R}, D\right)\right) \frac{\partial e^{S B}}{\partial \alpha_{R}}\left(\alpha_{R}, D\right) h(D) d D>0$ since $\frac{\partial e^{S B}}{\partial \alpha_{R}}>0$, i.e., a more "pro-firm" oriented regulator implements higher effort. Increasing $\alpha_{R}$ above $\alpha_{C}$ always improves the Executive's expected payoff. 